Environmental Assessment of the Near-net-shape Electrochemical Metallisation Process and the Kroll

- Electron Beam Melting Process for Titanium Manufacture

Aleksei Dolganov, Matthew T. Bishop, Marco Tomatis, George Z. Chen, Di Hu

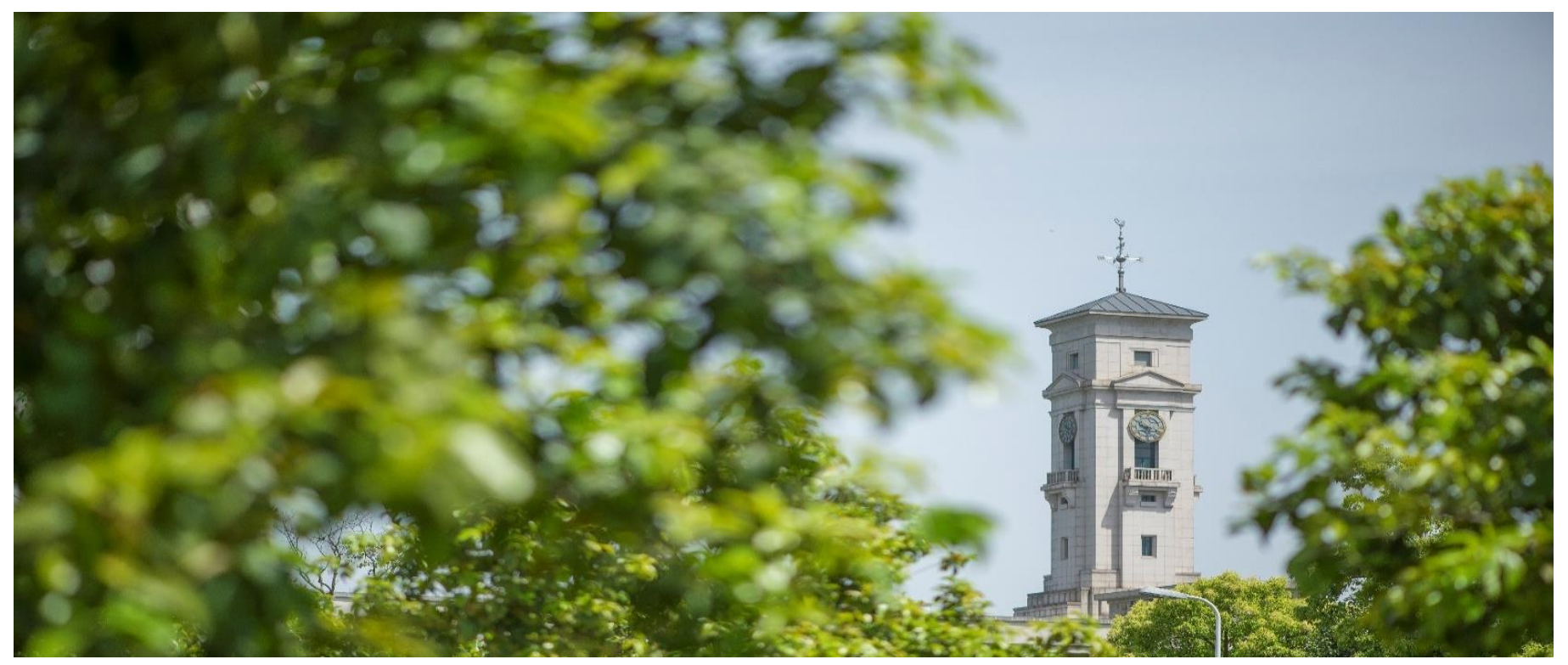


Faculty of Science and Engineering, University of Nottingham Ningbo China, 199 Taikang East Road, Ningbo, 315100, Zhejiang, China.

First published 2020

This work is made available under the terms of the Creative Commons Attribution 4.0 International License:

http://creativecommons.org/licenses/by/4.0

The work is licenced to the University of Nottingham Ningbo China under the Global University Publication Licence:

https://www.nottingham.edu.cn/en/library/documents/researchsupport/global-university-publications-licence.pdf 
Received 00th January 20xx, Accepted 00th January 20xx DOI: $10.1039 / x 0 x \times 00000 x$

\title{
Environmental Assessment of the Near-net-shape Electrochemical Metallisation Process and the Kroll - Electron Beam Melting Process for Titanium Manufacture
}

\author{
Aleksei Dolganov ${ }^{a}$, Matthew T. Bishop ${ }^{\mathrm{a}, \mathrm{b}}$, Marco Tomatis ${ }^{\mathrm{c}}$, George Z. Chen ${ }^{\mathrm{a}, \mathrm{b}} \mathrm{d}^{*}, \mathrm{Di} \mathrm{Hu}^{\mathrm{a}, \mathrm{b}} \mathrm{e}^{*}$
}

\begin{abstract}
The enforcement of environmental policies, in recent years, has become one of the major driving forces for industrial upgrading. Therefore, this study is focused on the evaluation of the environmental impact of a newly proposed titanium additive manufacturing process, including its in-depth comparison with the conventional method. This new method, referred to as Near-net-shape Electrochemical Metallisation, is based on the in-situ metallisation (via the FFC-Cambridge Process) of 3D-printed titanium oxide precursors (using Direct Ink Writing Process). In order to evaluate the main contributors to the environmental damage and to compare them with the conventional route for titanium manufacturing, the gate-to-gate Life Cycle Assessment has been conducted following established international standards. From this, the main contributors within the Near-net-shape Electrochemical Metallisation process were identified to be electricity and synthetic rutile, with medium impacts from argon and nickel. It was found that major impacts were challenging to be reduced without affecting the properties of the final product. However, the medium impacts can theoretically be modified, yielding potential improvements in the sustainability of the process by $10 \%$. When compared to the conventional route (consisting of the Kroll Process, Free Fall Gas Atomisation and Electron Beam Melting), the end point results demonstrated that, by adopting the Near-net-shape Electrochemical Metallisation Process, the overall impact of titanium fabrication was dramatically reduced. Specifically, an average reduction of $68 \%$ for the ecosystem, human health and resources was observed.
\end{abstract}

\section{Introduction}

Titanium is extensively used in numerous industries, such as biomedical [1, 2], architectural [3], aerospace [4] and others [57]. This high demand is caused by the wide range of unique properties of titanium including biocompatibility, low density and high strength [8]. However, the extraction and fabrication of titanium are energy and resource-intensive processes [9]. Therefore, an optimisation for both the extraction and fabrication processes is required to lower both energy input and material waste. The majority of titanium is currently extracted via the Kroll Process, which was invented in the 1940s, and commercialised in 1950s [10, 11]. In an effort to improve the extraction process for titanium, substantial work has been

\footnotetext{
a. Department of Chemical and Environmental Engineering, The University of Nottingham Ningbo China, 315100, PR China.

b. International Doctoral Innovation Centre, The University of Nottingham Ningbo China, Ningbo, 315100, PR China.

Sustainable Industrial Systems, School of Chemical Engineering and Analytical Science, The University of Manchester, Manchester, UK.

d. Department of Chemical and Environmental Engineering, Advanced Materials Research Group, Faculty of Engineering, The University of Nottingham, Nottingham NG7 2RD, UK.

e. Advanced Energy and Environmental Materials \& Technologies Research Group,

The University of Nottingham Ningbo China, Ningbo, 315100, PR China.

* Corresponding authors: George.Chen@nottingham.ac.uk;

Di.Hu@nottingham.edu.cn
}

made to develop simpler, faster and more efficient extraction methods such as the Armstrong Process [12], $\mathrm{H}_{2}$ assisted magnesiothermic reduction [13], the Solid-Oxide-Membrane (SOM) Process [14], the Ono-Suzuki Process [15], Electrolysis of Carbo-Sulfurized Titanium Dioxide [16] and the Fray-FarthingChen (FFC)-Cambridge Process [17]. Among these techniques, the FFC-Cambridge Process has the unique ability for the nearnet-shape conversion of metal oxide precursors into their metal or alloy counterparts [9, 18-20]. By taking advantage of a proper method for the fabrication of metal oxide precursors, the FFCCambridge Process can be utilised to integrate the extraction process with the fabrication process for titanium manufacture. It is worth mentioning here that the cost for fabricating the extracted titanium into its final products could account for more than half of the total cost, therefore, this technique can be applied in combination with a fabrication technique to potentially reduce waste, environmental impact and cost [9]. Traditionally, the fabrication of highly demanded titanium components has created a large amount of waste, due to the complexity of the desired structures and shapes, while machining of titanium reduces the lifespan of the milling tools due to the phase transformation induced during the process [21-24]. In order to address these problems, Powder Metallurgical (PM) methods have been developed [25]. Many different PM processes have been adapted for titanium fabrication such as Metal Injection Moulding (MIM) [26], Selective Laser Melting (SLM) [27], Electron Beam Melting 


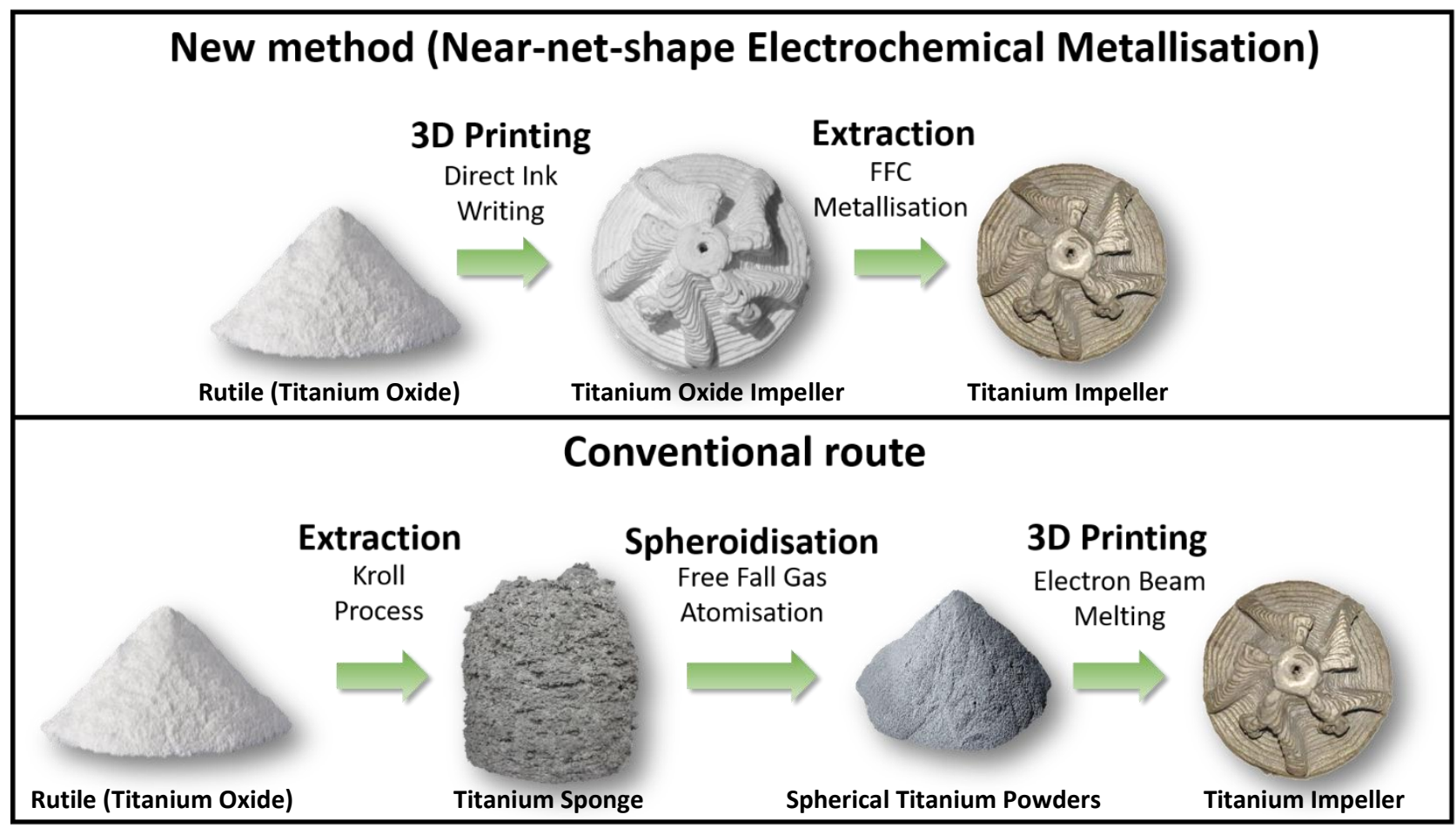

Figure 1: Comparison of the conventional and proposed routes for AM of titanium components.

(EBM) [28], Hot Isostatic Pressing (HIP) [29] and others [30-32]. Among these, the EBM Process has been considered as the standard for the relatively high-speed and highly flexible fabrication of titanium components, despite consuming large amounts of energy to sustain the electron beam [28, 33]. This method, however, requires high-quality spherical titanium powder as a feedstock, which inevitably adds pre-treatment steps to the manufacturing chain [34], such as Free Fall Gas Atomization (FFGA) [35, 36], Electrode Induction Gas Atomization [37], Plasma Atomization [38] or Plasma Rotating Electrode Process [38]. Between the abovementioned spherical titanium powder production methods, FFGA has emerged as the most suitable process, due to relatively low energy consumption, the high sphericity and narrow size distribution of the particles that, additionally, represent separate spheres with no internal voids $[39,40]$. Due to the prevalence of these techniques, the Kroll Process, FFGA and then EBM (thereafter is called the Kroll-EBM Process) have been selected in this study as the representative of the conventional titanium component manufacturing route for the purposes of the comparative environmental assessment.

Due to the complexity of the previously described procedure associated with the Kroll-EBM Process, a novel production method has been developed in this work, where the fabrication stage (i.e., the shaping process) is conducted prior to the metal extraction process: reversing the conventional route (Figure 1). This results in the feedstock being shaped and then metallised via the FFC-Cambridge Process $[19,20]$. Such direct metallisation of the 3D printed metal oxide is referred to as a Near-net-shape Electrochemical Metallisation (NEM) Process. The fabrication stage in the NEM Process consists of a highly affordable 3D printing technique, Direct Ink Writing (DIW),

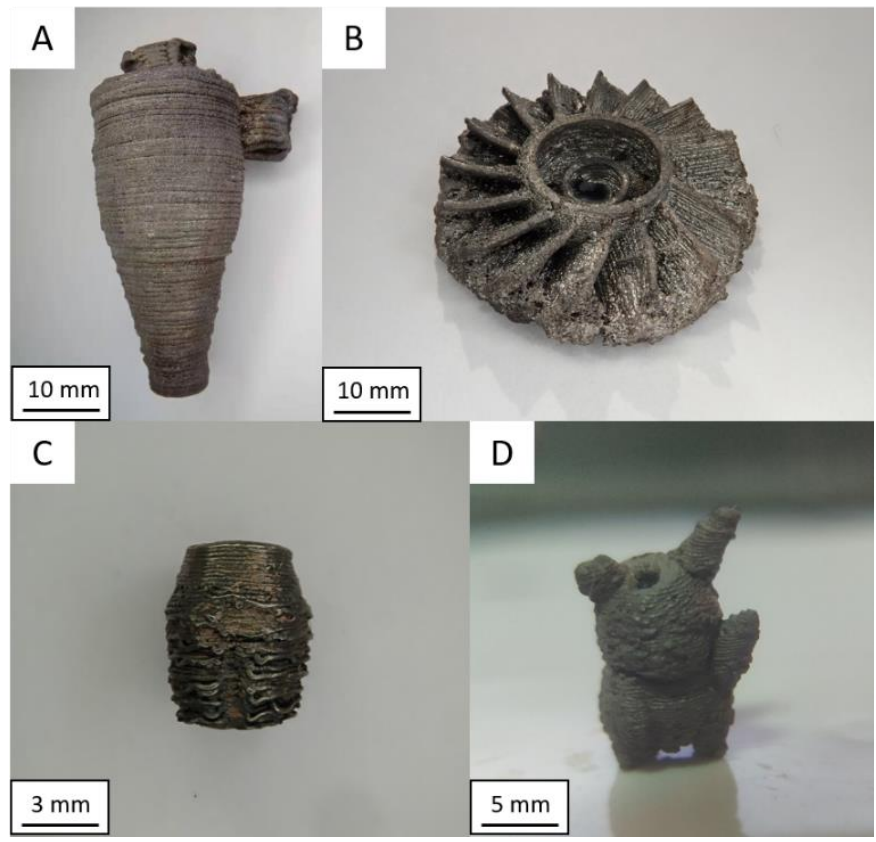

Figure 2: An example of the preliminary results of the NEM Process with a hydrocyclone (A), a turbine (B), a tooth implant (C) and a creature (D).

which has been applied for layer deposition of paste-like materials, including food, adhesives and metal oxide pastes [41, 42]. The shift of the 3D printing feedstock from spherical metal powder to metal oxide (Figure 1), with a corresponding in-situ electrochemical metallisation (i.e., FFC Metallisation), can dramatically reduce both the energy and material cost, as well as the related environmental impact [43]. It is important to notice that the proposed combination (the NEM Process) is not limited to any shape or material, meaning that it is possible to 


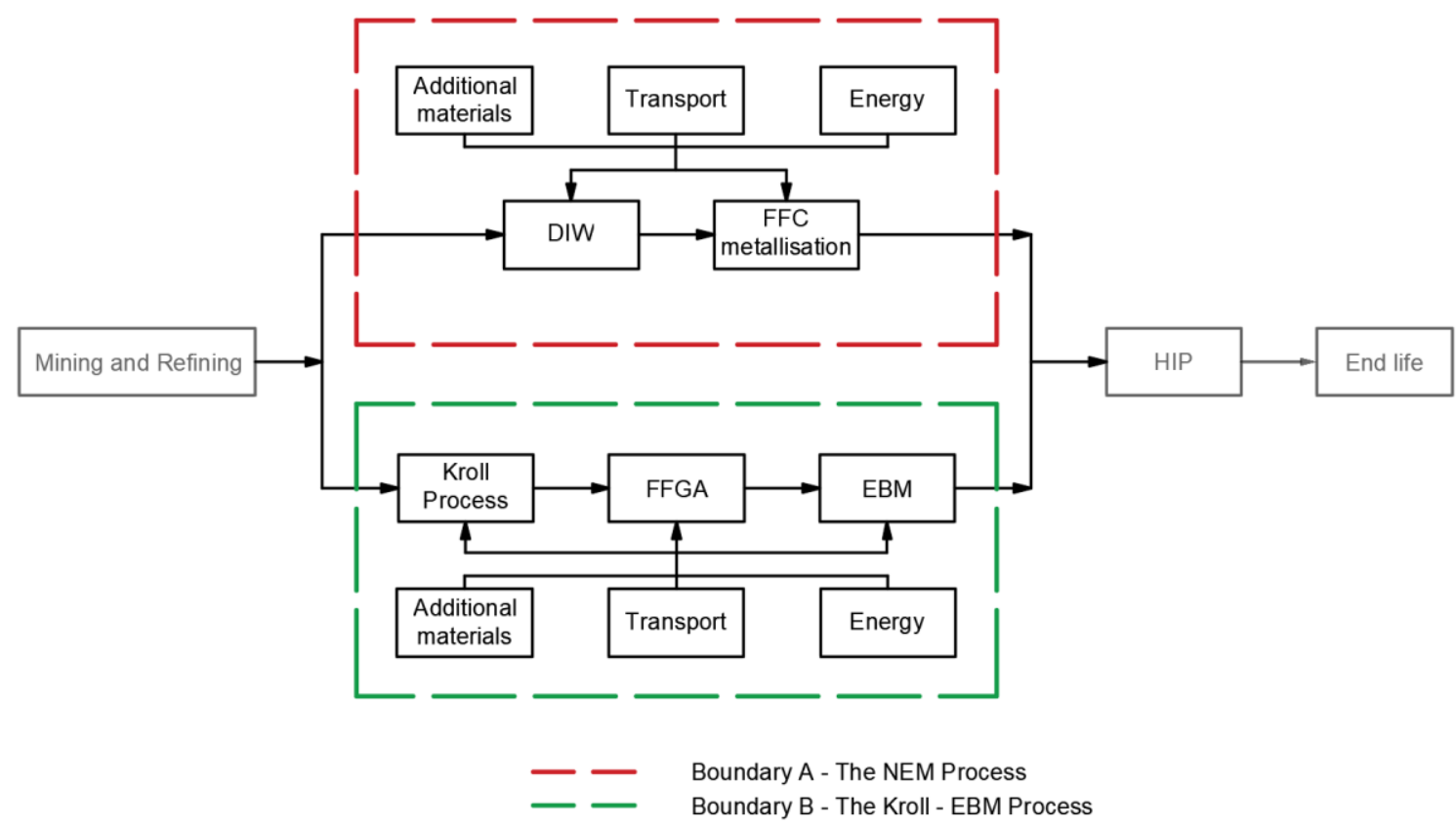

Figure 3: Manufacture routes of an additively produced (i.e. 3D-printed) titanium product; DIW - Direct Ink Writing; FFGA - Free Fall Gas Atomisation; EBM Electron Beam Melting; HIP - Hot Isostatic Pressing.

produce pure titanium by switching to pure $\mathrm{TiO}_{2}$ or even produce other metals and alloys (Figure 2 ). To determine the potential benefits of this method, it is crucial to quantify the environmental impact of the NEM Process in comparison to the conventionally adopted fabrication process (i.e. the Kroll-EBM Process). This is especially important due to new environmental policies, such as carbon taxes and emission trading schemes, which have increasingly gained the attention of multiple governments in the last few years [44-46]. It is important to highlight that these environmental policies have become one of the major factors for industrial change. This potentially allows a technique to become more favourable for future industries, despite the cost requirement for overhauling conventional processes.

In this work, for the first time, the introduction and the Life Cycle Assessment (LCA) of the NEM Process was performed in order to quantify its environmental impact and compare them to that of the conventional Kroll-EBM Process. Such assessment provides a quantitative analysis of the two processes with respect to all the material and energy inputs and outputs and their relative effect on the environment, human health and resource management [47]. Following the LCA approach, the relative contributions of the NEM Process production steps (i.e., extraction and fabrication) were investigated to determine which steps could be improved, to further reduce the environmental impact, which may disclose potential benefits for its commercialisation [47].

\section{Methodology}

This LCA was conducted according to the principles described in BS EN ISO 14044:2006+A1:2018 and BS EN ISO 14040:2006 [48, 49]. Accordingly, the systematic approach used for this study was divided into four main phases. The first phase of the LCA is the goal and scope definition, where the main goal is established, the level of detail and the system boundaries are set. Here the assumptions and limitations of the study are also stated. The second phase is the Life Cycle Inventory Analysis (LCIA). For this phase, the data sources are analysed and the required inputs and outputs are collected and applied to the LCA modelling software (SimaPro). The last two phases are the impact analysis and the interpretation of the gathered results. These stages of an LCA study summarise all the data prepared in the first two phases. The data collected during this study and the data generated through numerical modelling (i.e. using the LCA modelling software SimaPro), yield numerical estimations of the environmental effects that are divided into impact criteria, as discussed in the "Interpretation" and "Impact assessment and categories" sections.

\section{Goal and Scope:}

Two main goals were set for this study. First is to determine the environmental impact of the proposed NEM Process in comparison with that of the conventional Kroll-EBM Process. Second is to define the environmental impact of the NEM Process to propose adjustments that could further reduce its environmental impact.

For this study, the capability of producing one titanium impeller for pumps was selected as a Functional Unit (FU). This FU was set to show the feasibility for scaling up in the future. In addition, a cut-off value of $2 \%$ on environmental impact was selected to show the most relevant contributors.

Two boundaries have been generated (in Figure 3 Boundary A and $B$ ) that both have a fabrication technique (DIW and EBM, respectively) and a titanium extraction technique (FFC 


\section{Direct Ink Writing}

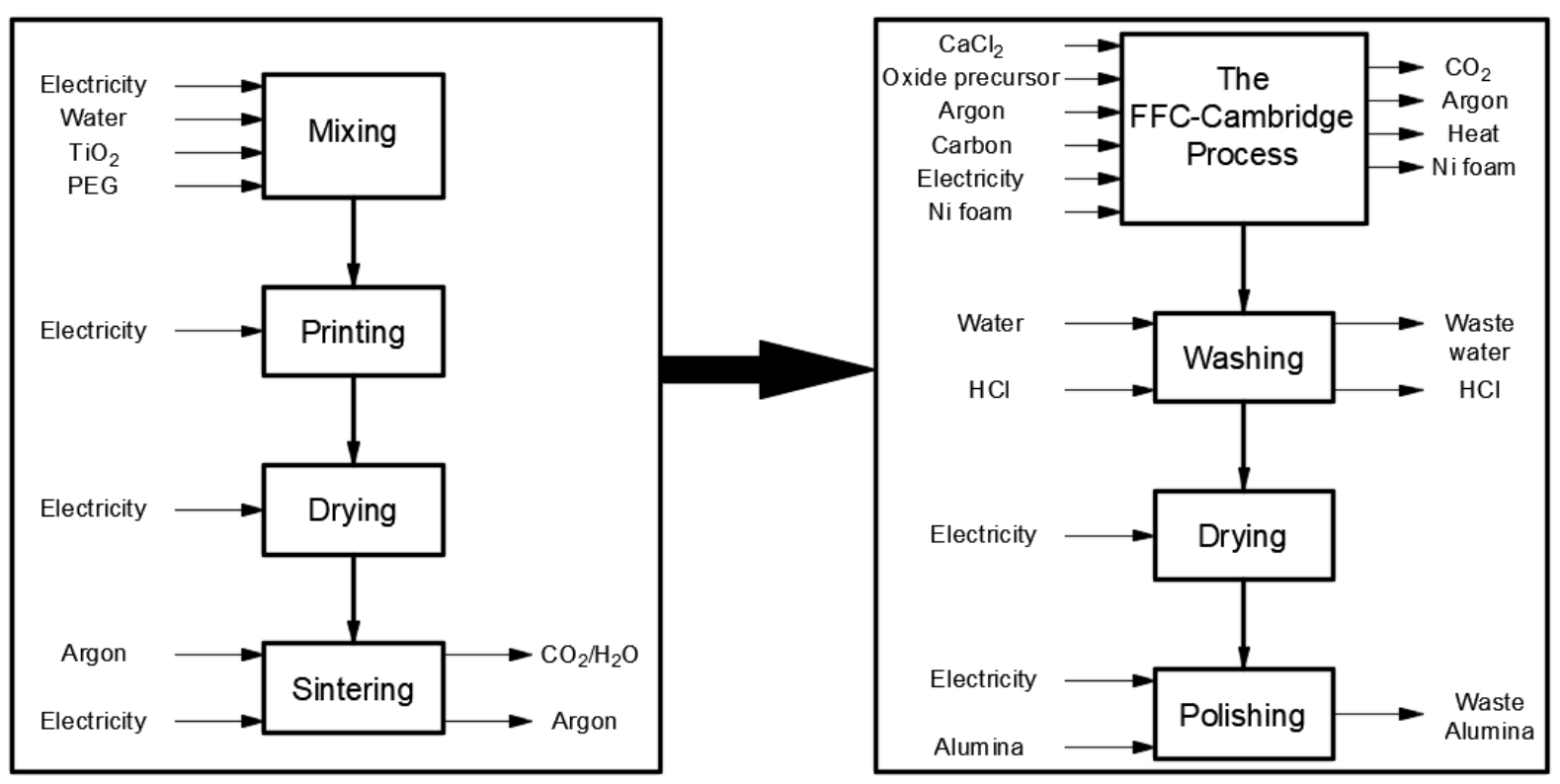

Figure 4: Detailed material and energy flow within the boundary A (the NEM Process).

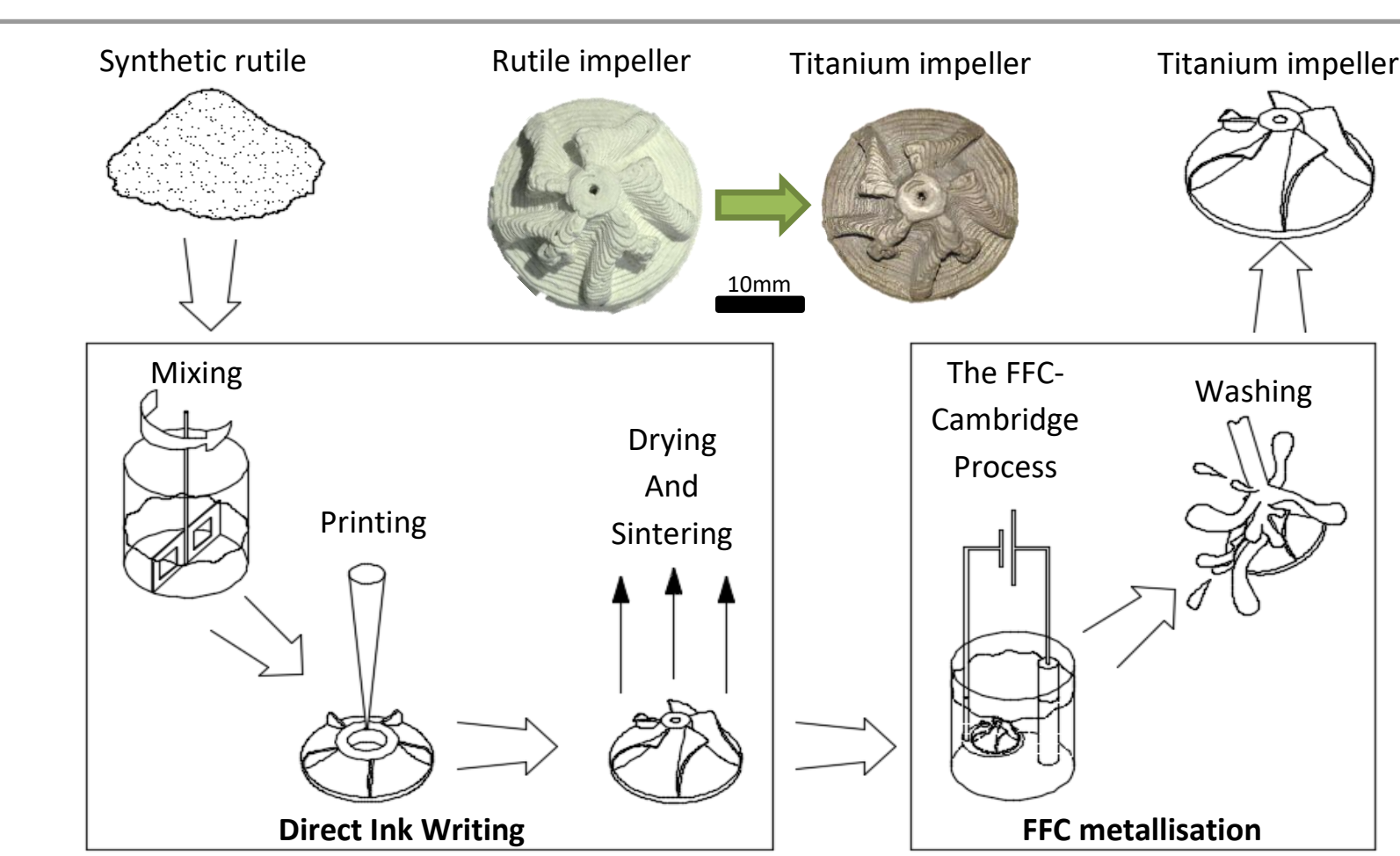

Figure 5: The NEM Process, showing the two stages used for fabrication of a titanium impeller from synthetic rutile. The rutile and titanium impellers produced via the NEM Process are shown for reference.

Metallisation and Kroll Process, respectively). To equalise the comparison of the evaluated processes, the same feedstock was selected: synthetic rutile; comprised of $95 \% \mathrm{TiO}_{2}$, as well as other trace elements with around $3 \%$ related to $\mathrm{Fe}_{2} \mathrm{O}_{3}$ and the remaining $2 \%$ attributed to various oxides of $\mathrm{Mn}, \mathrm{V}, \mathrm{Zr}, \mathrm{Cr}, \mathrm{Ca}$, $\mathrm{Mg}, \mathrm{Si}, \mathrm{Al}, \mathrm{P}, \mathrm{S}, \mathrm{Nb}$ (the exact composition of these oxides varies depending on the source of the synthetic rutile) [51]. The use of synthetic rutile results in a pure titanium final product for the Kroll Process (owing to the purification of $\mathrm{TiCl}_{4}$ after the carbochlorination process), however, the final products of the NEM Process will be affected by the presence of these trace elements, thus forming a novel alloy of titanium. It is important to highlight that this does not reduce the quality of the final product as these novel titanium alloys have been reported to 
Synthetic rutile

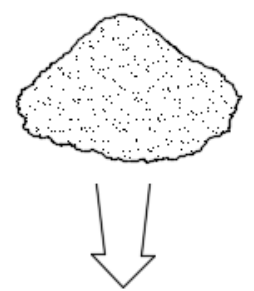

Titanium impeller

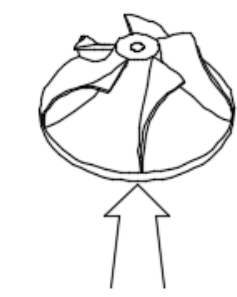

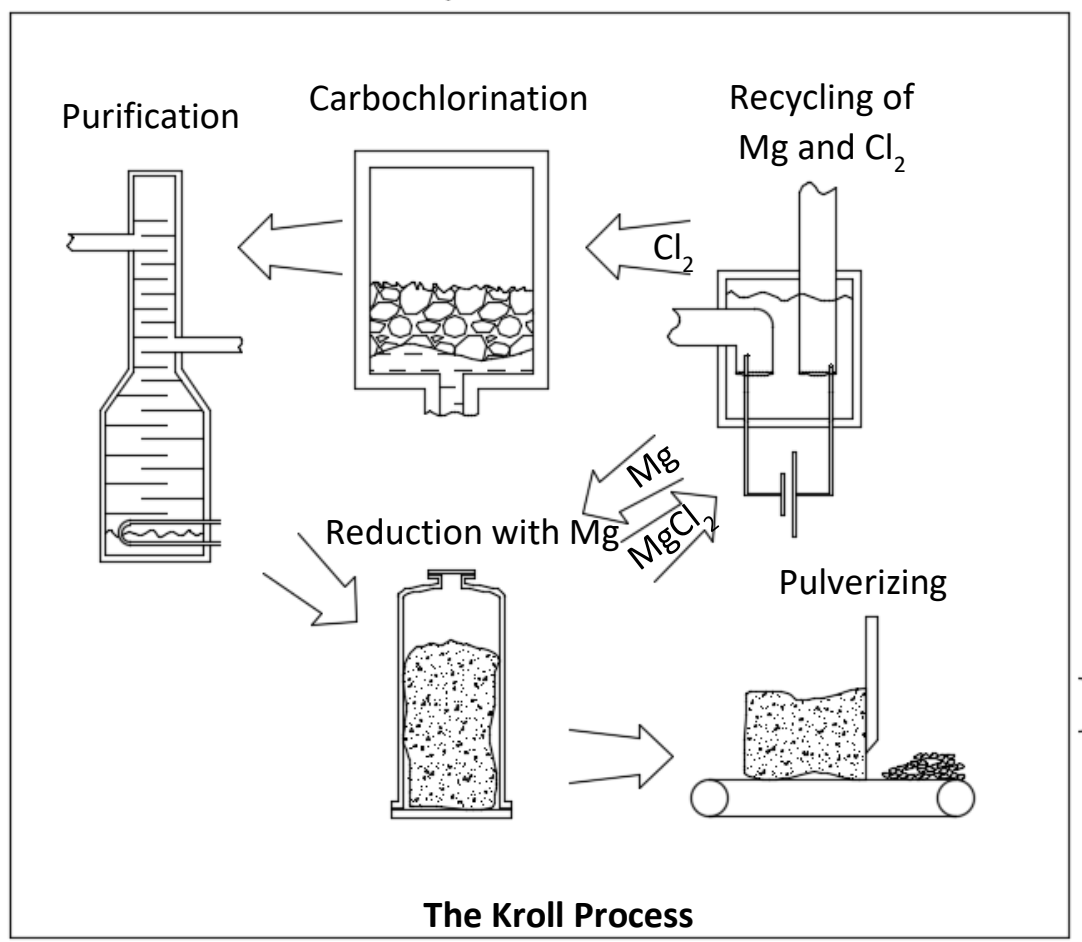

EBM

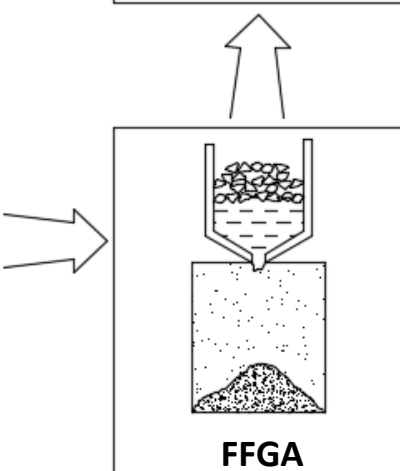

Figure 6: The Kroll-EBM Process, showing the three stages used for fabricating a titanium impeller from raw titanium dioxide.

meet the requirement for weldable titanium alloy armour plates and outperform the ASTM 4 standard [52], allowing for the formation of equivalent final products between the two techniques (i.e. the Kroll-EBM Process and the NEM Process). As the extraction and purification methods for the synthetic rutile are shared between the two investigated processes, it is assumed that they do not have an impact on the comparative study. Furthermore, the same assumption can be made for the life span and end life period of the produced items, as Hot Isostatic Pressing (HIP) was applied after both processes, in order to bring them to the highest relative density [50]. It is important to highlight that Boundary B (Figure $\mathbf{3}$ ) also includes an intermediate process for spheroidisation (i.e. FFGA) of titanium powder, as this production step is essential to increase the quality of the titanium powder to the required level for EBM [38].

The data used in this study have been allocated by mass.

\section{Case study:}

This work is considering two different production routes referred to as the NEM Process and the Kroll-EBM Process, respectively.

\section{The NEM Process}

Figure 4 describes all inputs and outputs of the NEM Process, along with a detailed list of sub-processes included in this Process. The NEM Process (i.e. the Boundary A in Figure 3) consists of two main stages (DIW and FFC metallisation), with a fabrication time of roughly three days (See Figure 5).

1. DIW.

This is an Additive Manufacturing (AM) method that utilises pastes or slurries as ink, which are extruded through a nozzle. Extrusion is facilitated via compressed air, which pushes the ink from the feed cylinder. Inks are prepared by mixing the solution of Polyethylene Glycol (PEG) and water with synthetic rutile powder (mainly titanium dioxide). After printing, the oxide precursor is dried for 24 hours. This sub-process takes roughly 27 hours.

- The printing technology utilised in the DIW step is modified from the Fused Deposition Modelling (FDM) Process, which allows for high-resolution printing and also has been considered to be one of the cheapest 3D printing technique on the market [42].

2. FFC Metallisation. 
Table 1: Inputs and outputs for the NEM Process to produce one titanium impeller ( 0.23 $\mathrm{kg}) .{ }^{*}$ Graphite is consumed following the anodic reaction.

\begin{tabular}{|c|c|c|c|c|c|c|}
\hline & & Name & Unit & DIW & $\begin{array}{c}\text { FFC } \\
\text { Metall- } \\
\text { isation }\end{array}$ & Total \\
\hline \multirow{14}{*}{$\begin{array}{l}\stackrel{n}{5} \\
\stackrel{0}{\Xi} \\
\underline{\Xi}\end{array}$} & \multicolumn{2}{|c|}{$\begin{array}{l}\text { Synthetic } \\
\text { rutile }\end{array}$} & $\mathrm{kg} / \mathrm{FU}$ & 0.4 & $\mathrm{n} / \mathrm{a}$ & 0.4 \\
\hline & \multicolumn{2}{|c|}{$\begin{array}{c}\text { Synthetic } \\
\text { rutile impeller }\end{array}$} & $\mathrm{kg} / \mathrm{FU}$ & $\mathrm{n} / \mathrm{a}$ & 0.4 & 0.4 \\
\hline & \multicolumn{2}{|c|}{ PEG } & $\mathrm{kg} / \mathrm{FU}$ & 0.08 & $\mathrm{n} / \mathrm{a}$ & 0.08 \\
\hline & \multicolumn{2}{|c|}{$\begin{array}{l}\text { Calcium } \\
\text { chloride }\end{array}$} & $\mathrm{kg} / \mathrm{FU}$ & $n / a$ & 0.8 & 0.8 \\
\hline & \multicolumn{2}{|c|}{ Argon } & $\mathrm{kg} / \mathrm{FU}$ & 0.01 & 0.49 & 0.5 \\
\hline & \multicolumn{2}{|c|}{ Graphite } & $\mathrm{kg} / \mathrm{FU}$ & $\mathrm{n} / \mathrm{a}$ & 0.06 & 0.06 \\
\hline & \multicolumn{2}{|c|}{ Nickel foam } & $\mathrm{kg} / \mathrm{FU}$ & $\mathrm{n} / \mathrm{a}$ & 0.005 & 0.005 \\
\hline & \multicolumn{2}{|c|}{ Water } & $\mathrm{kg} / \mathrm{FU}$ & 0.4 & 1.2 & 1.6 \\
\hline & \multicolumn{2}{|c|}{ Alumina } & $\mathrm{kg} / \mathrm{FU}$ & $n / a$ & 0.002 & 0.002 \\
\hline & \multicolumn{2}{|c|}{$\mathrm{HCl}$} & $\mathrm{kg} / \mathrm{FU}$ & $\mathrm{n} / \mathrm{a}$ & 0.0007 & 0.0007 \\
\hline & \multirow{4}{*}{ 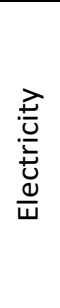 } & $\begin{array}{c}3 \mathrm{D} \\
\text { Printing }\end{array}$ & \multirow{4}{*}{$\mathrm{kWh} / \mathrm{FU}$} & 0.215 & $\mathrm{n} / \mathrm{a}$ & \multirow{4}{*}{8.05} \\
\hline & & $\begin{array}{l}\text { Sinter- } \\
\text { ing }\end{array}$ & & 0.015 & $\mathrm{n} / \mathrm{a}$ & \\
\hline & & $\begin{array}{l}\text { Metall- } \\
\text { isation }\end{array}$ & & $\mathrm{n} / \mathrm{a}$ & 7.76 & \\
\hline & & Misc. & & 0.03 & 0.03 & \\
\hline \multirow{10}{*}{\begin{tabular}{l}
$\frac{n}{2}$ \\
$\frac{0}{2}$ \\
\multirow{2}{7}{} \\
0
\end{tabular}} & \multicolumn{2}{|c|}{$\begin{array}{l}\text { Titanium } \\
\text { impeller }\end{array}$} & $\begin{array}{c}\mathrm{kg} \\
\text { (i.e. } \mathrm{FU})\end{array}$ & $\mathrm{n} / \mathrm{a}$ & 0.23 & 0.23 \\
\hline & \multicolumn{2}{|c|}{$\begin{array}{l}\text { Calcium } \\
\text { chloride }\end{array}$} & $\mathrm{kg} / \mathrm{FU}$ & $\mathrm{n} / \mathrm{a}$ & 0.8 & 0.8 \\
\hline & \multirow[t]{2}{*}{ O̊ } & $\begin{array}{l}\text { Metall- } \\
\text { isation* }\end{array}$ & $\mathrm{kg} / \mathrm{FU}$ & $\mathrm{n} / \mathrm{a}$ & 0.22 & \multirow[t]{2}{*}{0.38} \\
\hline & & PEG & & $\mathrm{n} / \mathrm{a}$ & 0.16 & \\
\hline & \multicolumn{2}{|r|}{ Argon } & $\mathrm{kg} / \mathrm{FU}$ & 0.01 & 0.49 & 0.5 \\
\hline & \multicolumn{2}{|c|}{ Nickel foam } & $\mathrm{kg} / \mathrm{FU}$ & $\mathrm{n} / \mathrm{a}$ & 0.005 & 0.005 \\
\hline & \multicolumn{2}{|c|}{ Alumina } & $\mathrm{kg} / \mathrm{FU}$ & $\mathrm{n} / \mathrm{a}$ & 0.002 & 0.002 \\
\hline & \multicolumn{2}{|c|}{$\mathrm{HCl}$} & $\mathrm{kg} / \mathrm{FU}$ & $\mathrm{n} / \mathrm{a}$ & 0.0007 & 0.0007 \\
\hline & \multicolumn{2}{|r|}{ Heat } & $\mathrm{kJ} / \mathrm{FU}$ & $\mathrm{n} / \mathrm{a}$ & 655 & 655 \\
\hline & \multicolumn{2}{|c|}{ Water } & $\mathrm{kg} / \mathrm{FU}$ & 0.4 & 1.2 & 1.6 \\
\hline
\end{tabular}

The 3D printed titanium oxide precursor undergoes electrochemical metallisation, also known as the FFCCambridge Process, using molten salt as the electrolyte to form the metallic titanium impeller $[9,17]$. During this process, the 3D printed titanium oxide precursor is wrapped in a nickel foam and attached to the current collector to form the cathodic assembly. Nickel foam has been utilised here because it can increase the connection area for electron conduction due to the flexibility of Nickel foam. The whole cathodic assembly is then placed in a sealed retort that has been kept at $900{ }^{\circ} \mathrm{C}$ and continuously flushed with argon. A graphite rod is used as the anode. When an appropriate voltage is applied between the cathode and the anode, the following electrochemical reactions can occur:

On the cathode:

$\mathrm{TiO}_{2}+4 e^{-}=\mathrm{Ti}+2 \mathrm{O}^{2}$

eq. 1
On the anode:

$\mathrm{C}+2 \mathrm{O}^{2-}=\mathrm{CO}_{2}+4 \mathrm{e}^{-}$or $2 \mathrm{C}+2 \mathrm{O}^{2-}=2 \mathrm{CO}+4 \mathrm{e}^{-}$

eq. 2

After 24-hour electrolysis, the product is cooled, washed in water and dilute $\mathrm{HCl}$, and then dried and polished by abrasive blasting. Overall, this stage takes about 30 hours and has numerous advantages:

- FFC metallisation uniquely allows for the in-situ metallisation of a metal oxide precursor into its metallic counterpart without major shape degradation [20]. Therefore, titanium extraction and shape fabrication can be integrated into one step during the NEM Process, which is the foundation of this process.

- It has also been demonstrated that it is possible to lower the overall environmental impact associated with the extraction of titanium by implementing the FFC-Cambridge Process instead of the conventionally applied Kroll Process [47].

- Additionally, the FFC-Cambridge Process has been demonstrated to be able to produce metal alloys directly from metal oxide mixtures without using a complex alloying procedure that would be required to manufacture metal alloys before the EBM Process [19, 53], giving an additional commercial benefit to the NEM Process.

- The produced titanium items are promising candidates to be implemented in medical implants without posttreatment due to the naturally occurring porous microstructure (close to that of the natural bones) of the product that is achieved after the FFC-Cambridge Process $[19,54]$.

\section{The Kroll-EBM Process}

The Kroll-EBM Process consists of three main stages and has a fabrication time of at least two weeks (See Figure 6):

\section{The Kroll Process.}

At this stage, synthetic rutile is transformed into an intermediate chemical species $\left(\mathrm{TiCl}_{4}\right)$ in the carbochlorination reaction:

$2 \mathrm{TiO}_{2}+4 \mathrm{Cl}_{2}+3 \mathrm{C}=2 \mathrm{TiCl}_{4}+2 \mathrm{CO}+\mathrm{CO}_{2}$

eq. 3 After purification, it is reduced using molten magnesium metal under vacuum.

$\mathrm{TiCl}_{4}+2 \mathrm{Mg}=\mathrm{Ti}+2 \mathrm{MgCl}_{2}$ eq. 4 The mixture is then distilled under vacuum, to remove all $\mathrm{MgCl}_{2}$. $\mathrm{Cl}_{2}$ and $\mathrm{Mg}$ are recovered via the electrolysis of the recycled $\mathrm{MgCl}_{2}$. The produced titanium has a porous structure and therefore is referred to as a titanium sponge, which is crushed at the end of the process. Overall, the Kroll Process takes about 2-3 weeks to produce a batch of titanium [10].

\section{FFGA.}

This process is used to transform the crushed titanium produced by the Kroll Process into a spherical shape, which offers the necessary flowability and packability required for the following EBM Process. In FFGA, titanium is converted into a molten phase and the resulting flow is broken down into small droplets via a stream of pressurised argon gas. The whole 
process normally takes about 3 hours to produce $50 \mathrm{~kg}$ of powder with a typical efficiency of $92.5 \%$ [55].

\section{EBM.}

At the beginning of the EBM Process, a chamber containing the FFGA treated titanium powder is placed under vacuum and preheated to about $750{ }^{\circ} \mathrm{C}$. After that, a 3000W electron beam is utilised to melt the titanium powder spread in thin layers, creating a 2D pattern that is produced from the CAD model of an object [56]. By stacking up these 2D patterns, a 3D structure can, therefore, be fabricated. The powder that has not been melted functions as a support, and after the process it is reused. This process requires a considerable amount of energy input due to the involved titanium heating and melting processes [57].

Figures $\mathbf{3}$ and $\mathbf{4}$ show the simplicity of the NEM Process over the Kroll-EBM Process. In addition, the NEM Process dramatically reduces the titanium impeller manufacturing period from about 2 weeks to 3 days.

\section{Life cycle inventory:}

Data used to evaluate the NEM Process were collected from a pilot-scale rig and are summarised in Table 1. As described in

Table 2: $\mathrm{LCl}$ of boundary $2[55,59] .{ }^{*}$ - For the complete list of the LCI for the Kroll Process refer to the supplementary information.

\begin{tabular}{|c|c|c|c|c|c|c|}
\hline & Name & Unit & $\begin{array}{c}\text { Kroll } \\
\text { Process } \\
*\end{array}$ & FFGA & EBM & Total \\
\hline \multirow{6}{*}{ 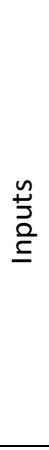 } & $\begin{array}{c}\text { Synthetic } \\
\text { Rutile }\end{array}$ & kg/FU & 8.7 & $n / a$ & $\mathrm{n} / \mathrm{a}$ & 8.7 \\
\hline & $\begin{array}{l}\text { Titanium } \\
\text { sponge }\end{array}$ & kg/FU & $\mathrm{n} / \mathrm{a}$ & 0.247 & $\mathrm{n} / \mathrm{a}$ & 0.247 \\
\hline & $\begin{array}{l}\text { Titanium } \\
\text { Powder }\end{array}$ & kg/FU & $n / a$ & $n / a$ & 0.23 & 0.23 \\
\hline & Argon & kg/FU & $n / a$ & 0.07 & $\mathrm{n} / \mathrm{a}$ & 0.07 \\
\hline & Water & $\mathrm{kg} / \mathrm{FU}$ & 0.1 & 35.6 & $\mathrm{n} / \mathrm{a}$ & 35.7 \\
\hline & Electricity & $\begin{array}{c}\mathrm{kWh} / \mathrm{F} \\
\mathrm{U}\end{array}$ & 5.4 & 0.45 & 11.39 & 17.24 \\
\hline \multirow{6}{*}{$\begin{array}{l}\stackrel{n}{2} \\
\stackrel{2}{0} \\
\frac{0}{7} \\
0\end{array}$} & $\begin{array}{c}\text { Titanium } \\
\text { metal }\end{array}$ & kg/FU & 0.247 & $\mathrm{n} / \mathrm{a}$ & $\mathrm{n} / \mathrm{a}$ & 0.247 \\
\hline & $\begin{array}{l}\text { Titanium } \\
\text { impeller }\end{array}$ & $\begin{array}{c}\mathrm{kg} \\
\text { (i.e. } \mathrm{FU})\end{array}$ & $n / a$ & $\mathrm{n} / \mathrm{a}$ & 0.23 & 0.23 \\
\hline & $\begin{array}{l}\text { Titanium } \\
\text { Waste }\end{array}$ & kg/FU & $\mathrm{n} / \mathrm{a}$ & 0.017 & $\mathrm{n} / \mathrm{a}$ & 0.017 \\
\hline & $\begin{array}{l}\text { Titanium } \\
\text { Powder }\end{array}$ & kg/FU & $\mathrm{n} / \mathrm{a}$ & 0.23 & $\mathrm{n} / \mathrm{a}$ & 0.23 \\
\hline & Argon & $\mathrm{kg} / \mathrm{FU}$ & $\mathrm{n} / \mathrm{a}$ & 0.07 & $\mathrm{n} / \mathrm{a}$ & 0.07 \\
\hline & Water & kg/FU & $\mathrm{n} / \mathrm{a}$ & 35.6 & $\mathrm{n} / \mathrm{a}$ & 35.6 \\
\hline
\end{tabular}

the case study section the synthetic rutile is mixed into a paste and extruded (via DIW) into the required shape. During drying and sintering, all water is evaporated and PEG from the green body is decomposed into $\mathrm{CO}_{2}$. Following the sintering stage, the FFC Metallisation converts synthetic rutile into titanium metal, which is done following the stoichiometry of equations 1 and 2 . The graphite anode is consumed and combined with oxygen, generating more $\mathrm{CO}_{2}$. All additional outputs are treated as waste (except for the product), gases are emitted to the atmosphere and metal scrap is sent to a recycling factory.

Operation data, describing the Kroll-EBM Process, were acquired from the following relevant studies (see Table 2 ). Information on the Kroll Process was used from the model provided in the Ecoinvent database, which was verified against data provided by Gao et al. [10, 58]. Data for the FFGA Process were discussed in the work of Serres et al., who compared a new AM method (Construction Laser Additive Directe $-C^{-} L A D^{\circledR}$ ) with conventional machining [55]. Finally, information for the EBM Process was taken from the work that compared EBM with conventional machining, conducted by Le et al. [59]. The data summarised in Table 2 shows a huge energy consumption of the EBM Process compared with the Kroll Process and FFGA. This is due to the time required for the EBM to form a product, which can reach 12 hours for one part [59].

Materials and background processes used to model the described production processes were taken from the Ecoinvent 3.0 database [58].

A parametric and sensitivity analysis was performed for the key contributors by varying their consumption $\pm 5 \%$ to establish the stability of the model and made assumptions.

Table 3: Summarised abbreviations

\begin{tabular}{|c|c|}
\hline $\begin{array}{l}\text { Endpoint } \\
\text { Groups of } \\
\text { Impact } \\
\text { Categories }\end{array}$ & Midpoint Impact Categories \\
\hline $\begin{array}{l}\text { Human } \\
\text { Health }\end{array}$ & $\begin{array}{l}\text { FPMF: Fine Particulate Matter Formation } \\
\text { GW: Global Warming } \\
\text { HCT: Human Carcinogenic Toxicity } \\
\text { HNCT: Human Non-Carcinogenic Toxicity } \\
\text { IR: Ionizing Radiation } \\
\text { OFHH: Ozone Formation on Human Health } \\
\text { OFTE: Ozone Formation on Terrestrial } \\
\text { Ecosystems } \\
\text { SOD: Stratospheric Ozone Depletion }\end{array}$ \\
\hline Ecosystem & $\begin{array}{l}\text { FE: Freshwater Eutrophication } \\
\text { FET: Freshwater Ecotoxicity } \\
\text { GW: Global Warming } \\
\text { TA: Terrestrial Acidification } \\
\text { TET: Terrestrial Ecotoxicity }\end{array}$ \\
\hline Resources & $\begin{array}{l}\text { FRS: Fossil Resource Scarcity } \\
\text { MRS: Mineral Resource Scarcity }\end{array}$ \\
\hline $\begin{array}{l}\text { Non- } \\
\text { Endpoint } \\
\text { Category }\end{array}$ & $\begin{array}{l}\text { LU: Land Use } \\
\text { ME: Marine Eutrophication } \\
\text { WC: Water Consumption }\end{array}$ \\
\hline
\end{tabular}




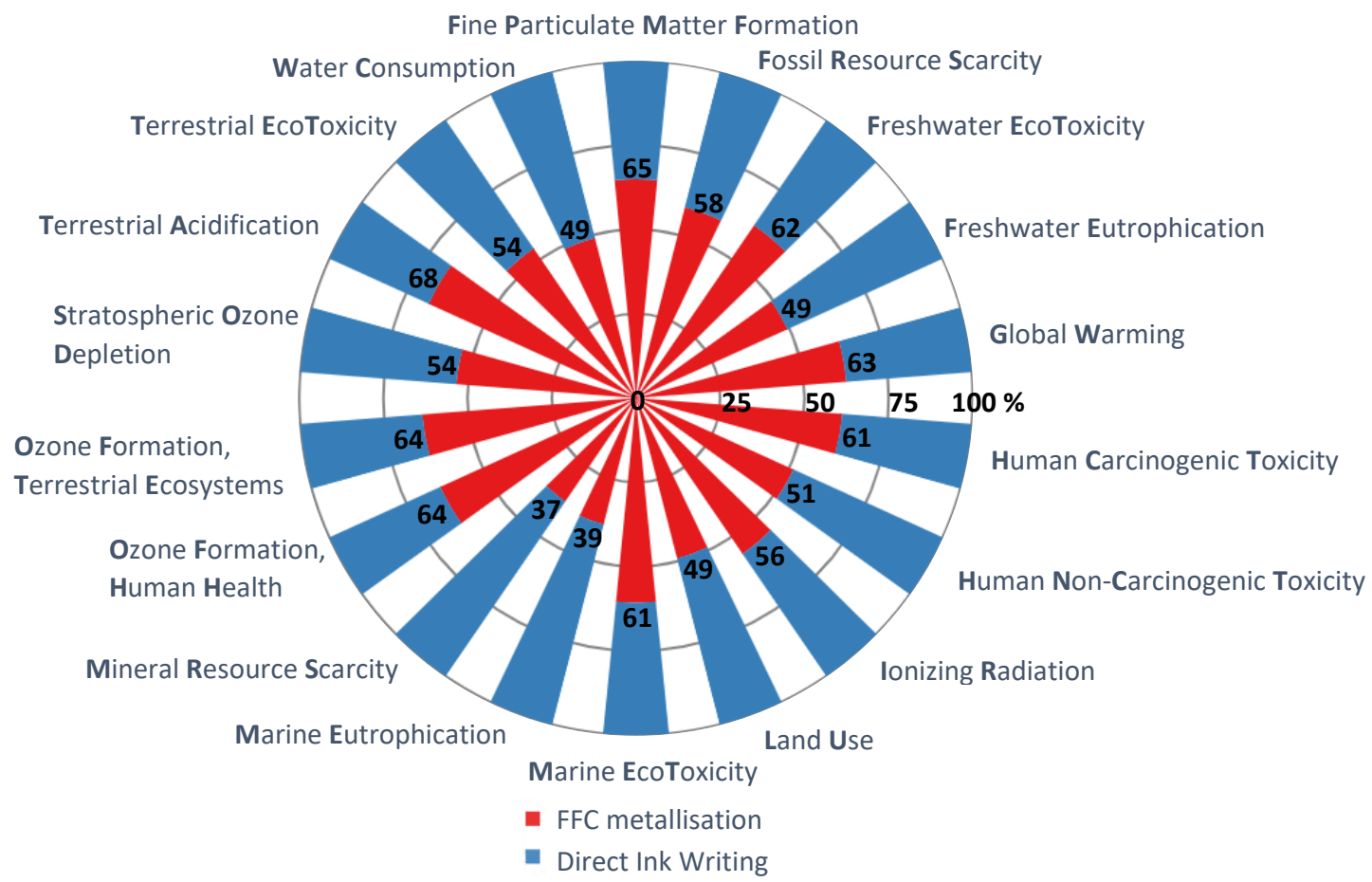

Figure 7: Impact analysis of contribution of the sub-processes for the NEM Process.

\section{Interpretation:}

The Impact for a single FU is produced for every impact criteria and completed using SimaPro software version 8.5.2.0, which utilises collected data and data from a dedicated database to numerically estimate and categorise the environmental impact of a process, following the selected method, as discussed below [60].

\section{Impact assessment and categories:}

All of the Life Cycle Impact assessments described in this study were performed according to the ReCiPe method at midpoint level, to achieve a higher degree of accuracy for the calculation and also produce a clearer picture about the investigated processes [61]. Impact categories considered by this method are listed in Table $\mathbf{3}$.

Endpoint characterisation summarises the impact from the above 15 criteria into three main groups: human health, ecosystem and resources (see Table 3 ). This summarisation increases statistical uncertainties but concisely shows the overall picture.

\section{Results and Discussion}

\section{Contribution analysis:}

The proposed NEM Process consists of two main sub-processes: DIW and FFC Metallisation. Based on the calculation results shown in the Figure 7, the FFC Metallisation sub-process emerged as the main contributor in 13 out of 18 impact categories (62.6\% for GW, $53.5 \%$ for SOD, $56 \%$ for IR, $63.8 \%$ for OFHH, $64.9 \%$ for FPMF, $63.6 \%$ for OFTE, $67.6 \%$ for TA, $53.8 \%$ for TET, $62.1 \%$ for FET, $60.7 \%$ for MET, $61.4 \%$ for HCT, $51.3 \%$ for HNCT, and $58.4 \%$ for FRS). In addition, most of the energy consumed in the process is dedicated to the FFC Metallisation stage. However, for the WC, FE, ME, LU and MRS impact categories, the DIW Process was shown to be the main contributor. This can be linked to the refining and mining of synthetic rutile used in the process (see Figure 8), which produces solid waste and requires considerable land use [62].

Figure 8 displays the source of the high contributors, in the NEM Process, to the allocated impact categories. The majority of impacts are allocated to electricity and the feedstock. For IR and WC (underlined in green in Figure 8 to highlight these categories), however, the impact of argon use overcomes that of electricity. This happened due to the nature of the production process of argon. During this process coproducts, such as krypton and xenon, are formed, which are considered as radionuclides in ReCiPe [63]. In addition to that, the separation of argon from the air also removes moisture that results in a high level of water consumption (WC) indicated in the assessment method [64]. Another area of the interest is the influence of nickel. It has relatively high impacts of $10.6 \%, 14.9 \%$ and $13.7 \%$ for FPMF, TA and HNCT, respectively. These categories are underlined in purple in Figure 8 to highlight them. The impact on FPMF originated from the crushing step of the nickel ore during the refining and excavation processes, 


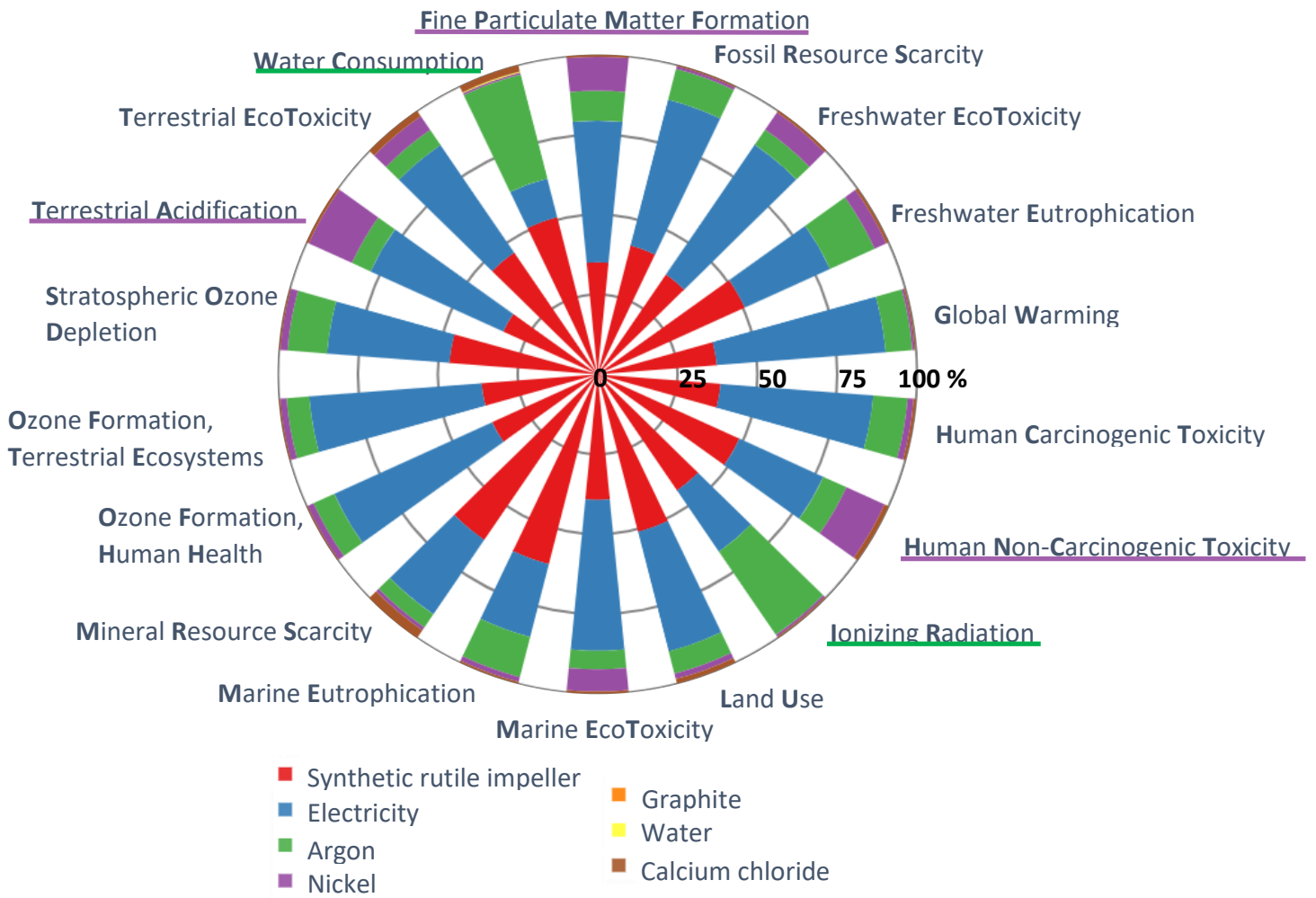

\begin{tabular}{|c|c|c|c|c|c|c|c|c|}
\hline Categories & Units & $\begin{array}{c}\text { Titanium oxide } \\
\text { impeller DIW }\end{array}$ & Calcium chloride & Argon & Graphite & Nickel & Water & Electricity \\
\hline GW & $\mathrm{kg} \mathrm{CO}_{2}$ eq & $3.8 \mathrm{E}+00$ & $4.2 \mathrm{E}-02$ & $8.4 \mathrm{E}-01$ & $1.3 \mathrm{E}-03$ & 7.2E-02 & $5.2 \mathrm{E}-06$ & $5.3 \mathrm{E}+00$ \\
\hline OD & kg CFC11 eq & $1.2 \mathrm{E}-06$ & $1.1 \mathrm{E}-08$ & $3.1 \mathrm{E}-07$ & $5.9 \mathrm{E}-10$ & $5.8 \mathrm{E}-08$ & $1.6 \mathrm{E}-12$ & $9.6 \mathrm{E}-07$ \\
\hline $\mathrm{IR}$ & kBq Co-60 eq & $1.5 \mathrm{E}-01$ & $1.4 \mathrm{E}-03$ & $1.1 \mathrm{E}-01$ & $6.8 \mathrm{E}-05$ & $2.3 \mathrm{E}-03$ & $1.9 \mathrm{E}-07$ & $7.8 \mathrm{E}-02$ \\
\hline OFHH & $\mathrm{kg} \mathrm{NO}_{x}$ eq & $8.1 \mathrm{E}-03$ & $9.1 \mathrm{E}-05$ & $1.6 \mathrm{E}-03$ & $3.8 \mathrm{E}-06$ & $4.5 \mathrm{E}-04$ & $1.2 \mathrm{E}-08$ & $1.2 \mathrm{E}-02$ \\
\hline FPMF & $\mathrm{kg}$ PM2.5 eq & $6.7 \mathrm{E}-03$ & $1.1 \mathrm{E}-04$ & $1.8 \mathrm{E}-03$ & $3.3 \mathrm{E}-06$ & $2.0 \mathrm{E}-03$ & $8.5 \mathrm{E}-09$ & $8.4 \mathrm{E}-03$ \\
\hline OFTE & $\mathrm{kg} \mathrm{NO}_{\mathrm{x}} \mathrm{eq}$ & $8.2 \mathrm{E}-03$ & $9.2 \mathrm{E}-05$ & $1.6 \mathrm{E}-03$ & $3.9 \mathrm{E}-06$ & $4.6 \mathrm{E}-04$ & $1.3 \mathrm{E}-08$ & $1.2 \mathrm{E}-02$ \\
\hline TAC & $\mathrm{kg} \mathrm{SO}_{2} \mathrm{eq}$ & $1.5 \mathrm{E}-02$ & $3.5 \mathrm{E}-04$ & $2.9 \mathrm{E}-03$ & $6.0 \mathrm{E}-06$ & $6.7 \mathrm{E}-03$ & $1.6 \mathrm{E}-08$ & $2.1 \mathrm{E}-02$ \\
\hline $\mathrm{FE}$ & $\mathrm{kg} P$ eq & $1.4 \mathrm{E}-03$ & $2.2 \mathrm{E}-05$ & $4.2 E-04$ & $5.0 \mathrm{E}-07$ & $1.1 \mathrm{E}-04$ & 1.7E-09 & $8.0 \mathrm{E}-04$ \\
\hline $\mathrm{ME}$ & $\mathrm{kg} \mathrm{N}$ eq & $1.3 \mathrm{E}-04$ & $1.3 \mathrm{E}-06$ & $2.8 \mathrm{E}-05$ & $3.2 \mathrm{E}-08$ & $3.1 \mathrm{E}-06$ & $2.1 \mathrm{E}-10$ & $5.0 \mathrm{E}-05$ \\
\hline TET & kg 1,4-DCB & $4.7 \mathrm{E}+00$ & $2.1 \mathrm{E}-01$ & $5.7 \mathrm{E}-01$ & $1.2 \mathrm{E}-03$ & $5.3 \mathrm{E}-01$ & $2.5 \mathrm{E}-05$ & $4.1 \mathrm{E}+00$ \\
\hline FET & kg 1,4-DCB & $1.1 \mathrm{E}-01$ & $2.1 \mathrm{E}-03$ & $1.7 \mathrm{E}-02$ & $2.3 \mathrm{E}-05$ & $2.0 \mathrm{E}-02$ & $2.3 \mathrm{E}-07$ & $1.5 \mathrm{E}-01$ \\
\hline MET & kg 1,4-DCB & $1.6 \mathrm{E}-01$ & $2.9 \mathrm{E}-03$ & $2.3 \mathrm{E}-02$ & $3.1 \mathrm{E}-05$ & 2.7E-02 & $3.3 \mathrm{E}-07$ & $1.9 \mathrm{E}-01$ \\
\hline HCT & kg 1,4-DCB & $1.1 \mathrm{E}-01$ & $2.1 \mathrm{E}-03$ & $3.0 \mathrm{E}-02$ & $5.1 \mathrm{E}-05$ & $5.4 \mathrm{E}-03$ & $6.5 \mathrm{E}-07$ & $1.3 \mathrm{E}-01$ \\
\hline HT & kg 1,4-DCB & $2.3 \mathrm{E}+00$ & $6.9 \mathrm{E}-02$ & $3.8 \mathrm{E}-01$ & 5.7E-04 & $6.3 \mathrm{E}-01$ & $6.0 \mathrm{E}-06$ & $1.4 \mathrm{E}+00$ \\
\hline LU & m2a crop eq & $7.1 \mathrm{E}-02$ & $2.1 \mathrm{E}-03$ & $1.0 \mathrm{E}-02$ & $2.2 \mathrm{E}-05$ & $2.4 \mathrm{E}-03$ & $1.5 \mathrm{E}-07$ & $5.4 \mathrm{E}-02$ \\
\hline RES & $\mathrm{kg}$ Cu eq & $5.1 \mathrm{E}-03$ & $2.5 \mathrm{E}-04$ & $4.0 \mathrm{E}-04$ & $1.4 \mathrm{E}-06$ & $9.0 \mathrm{E}-05$ & 9.7E-08 & $2.3 \mathrm{E}-03$ \\
\hline FRS & kg oil eq & $8.3 \mathrm{E}-01$ & $8.3 \mathrm{E}-03$ & $2.0 \mathrm{E}-01$ & $2.9 \mathrm{E}-04$ & $1.7 \mathrm{E}-02$ & $1.1 \mathrm{E}-06$ & $9.4 \mathrm{E}-01$ \\
\hline WC & $\mathrm{m}^{3}$ & $3.1 \mathrm{E}-02$ & $1.3 \mathrm{E}-03$ & $2.1 \mathrm{E}-02$ & $5.4 \mathrm{E}-06$ & $3.8 \mathrm{E}-04$ & $1.9 \mathrm{E}-04$ & $7.7 \mathrm{E}-03$ \\
\hline
\end{tabular}

Figure 8: Environmental impact contribution for the impeller production by the NEM Process. Underlined categories are highlighting key impactful areas for Argon (green) and Nickel (purple). The table contains the numerical values for every category.

thereby forming fine matter particles [65]. TA is impacted due to acid leaching stages implemented during the metal refining stages of nickel, which in turn results in the increased acid consumption and disposal [65]. The increase seen for HNCT is related to the coproducts that are extracted during the leaching, such as cobalt, copper, and gases like $\mathrm{SO}_{2}$ and $\mathrm{CO}_{2}$. Both cobalt and copper have been reported to be a noncarcinogenic toxic material and thus are considered as the factors affecting $\mathrm{HNCT}$ [66]. In addition, both $\mathrm{SO}_{2}$ and $\mathrm{CO}_{2}$ gases are classified as toxic materials according to the Environmental Protection Agency (EPA) classifications [67].

Therefore, the impact of FFC Metallisation could be lowered significantly by reducing argon consumption and reusing nickel electrode materials (as shown in Figure 8). Currently, argon is an essential input for the FFC Metallisaion, as it purges produced gases (i.e. $\mathrm{CO}_{2}$ and/or $\mathrm{CO}$ ) from the reactor and 


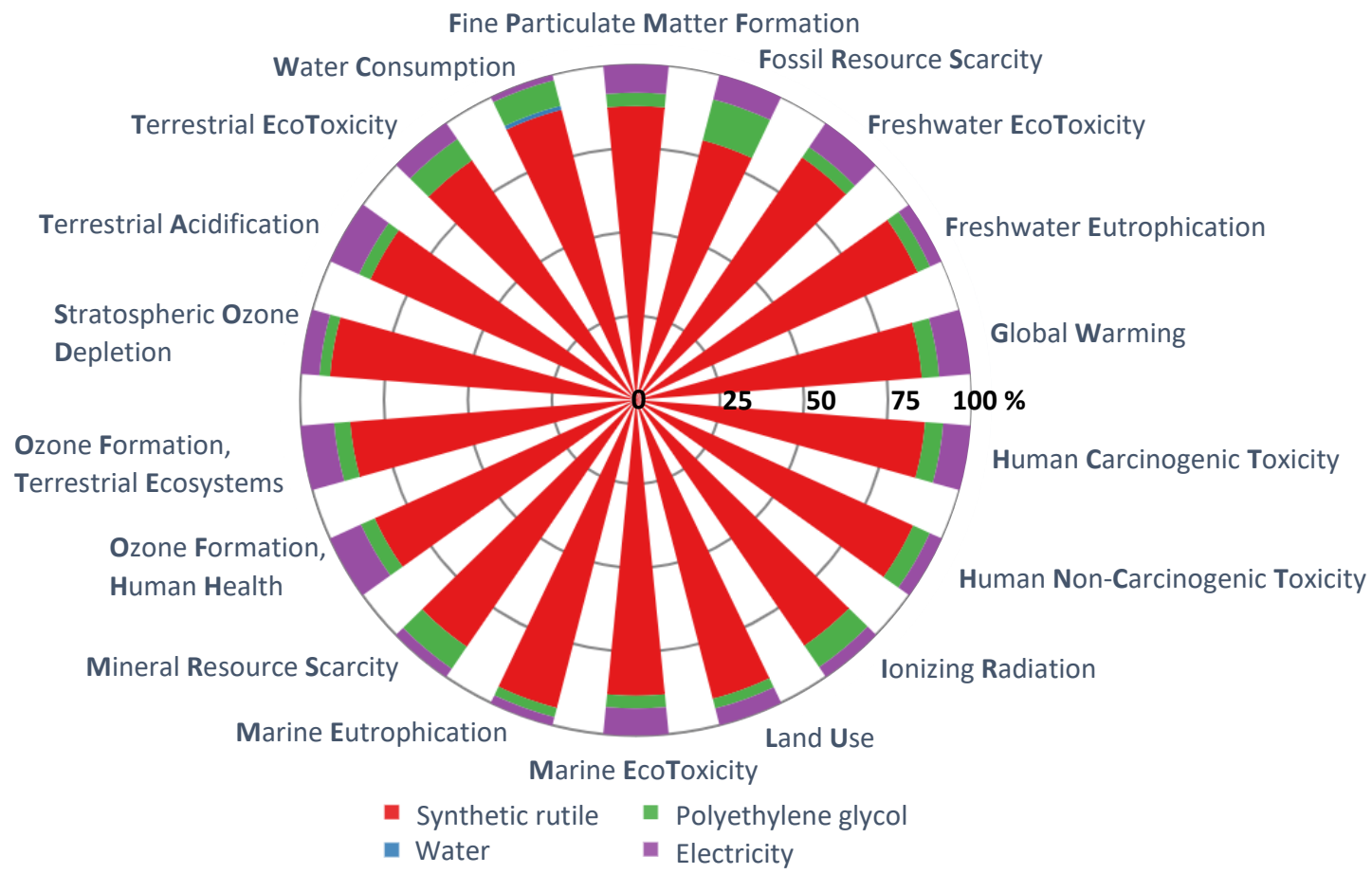

Figure 9: Environmental impact contributors for the DIW process.

ensures a low oxygen partial pressure to facilitate the deoxidation of synthetic rutile. However, its flow rate could potentially be reduced by optimising the design of the reactor. Reduction of argon flow rate from $0.2 \mathrm{l} / \mathrm{min}$ to $0.1 \mathrm{l} / \mathrm{min}$ can theoretically reduce the impact of some impact categories up to $20 \%$ (SOD, IR, FE, ME and WC). In addition, it is possible to implement a non-constant flow rate (i.e. smart flow control) for the argon as the production of abovementioned off-gases reduces exponentially during the FFC Metallisation, thus requiring less argon to purge them out after about $10 \mathrm{~h}$ from the beginning of the electrolysis process. Alternatively, a more optimised cell design, to separate/isolate the anode gas, $\mathrm{O}_{2}$ or $\mathrm{CO}_{2}$, from the rest of the cell can allow for the reduction of argon required. Furthermore, argon can be replaced by another cheaper inert gas, e.g. nitrogen, or even steam with an appropriate anode [9].

Nickel is used in the process to ensure a high surface connection between the metal oxide precursor and the current collector. In the current process, the nickel foam cannot be reused after the FFC Metallisation due to it becoming brittle, and is therefore disposed of after each FFC Metallisation cycle, adding to the environmental impact. This can be improved in two ways:

1. Using another material.

- Stainless steel - Cheap, resistant and relatively environmentally friendly.

- Titanium - Chemically stable in molten $\mathrm{CaCl}_{2}$, results in the minimum amount of impurities to the product.

2. Implement a reusable assembly.

- Develop a design that withstands molten $\mathrm{CaCl}_{2}$ and survives multiple batches, but is only used for the production of one shape.
From these two suggested improvements, it can be stated that implementing a reusable assembly is more effective. However, since the relative impact nickel has on the system is small, replacing it reflects only in a minor reduction for every category. A more detailed comparison of these implementations is discussed later in the Parametric and Sensitivity Analysis section.

The analysis of midpoint impacts of the DIW Process (see Figure 9) shows that the utilisation of synthetic rutile dominates in every category. This is directly linked to the amount of material used in this stage. Based on the acquired results, it is clear that the improvement of the DIW Process is very challenging due to the contributors that are involved, as the amount of synthetic rutile utilised cannot be reduced. It is worth mentioning here that the direct metallisation of naturally occurring rutile ore (i.e. beach sand) into titanium alloys has been successfully demonstrated [52]. This could be used within the NEM Process to further reduce the environmental impact, as the refining process for the feedstock would be dramatically simplified, however, it may also alter the physical properties of the metal oxide precursor and its metallised product.

\section{Parametric and Sensitivity Analysis:}

An analysis of the stability of the produced model is done via changing the main contributor (Electricity), established during the $\mathrm{LCl}$ stage, by $5 \%$. This shows the effect of the $\mathrm{LCl}$ values on the environmental impact. Increasing the energy consumption inevitably increased the carbon footprint from 10.05 to $10.31 \mathrm{~kg}$ $\mathrm{CO}_{2}$ eq, a $3 \%$ change from the initial state. Improvement in the energy consumption showed that the environmental impact of 
A

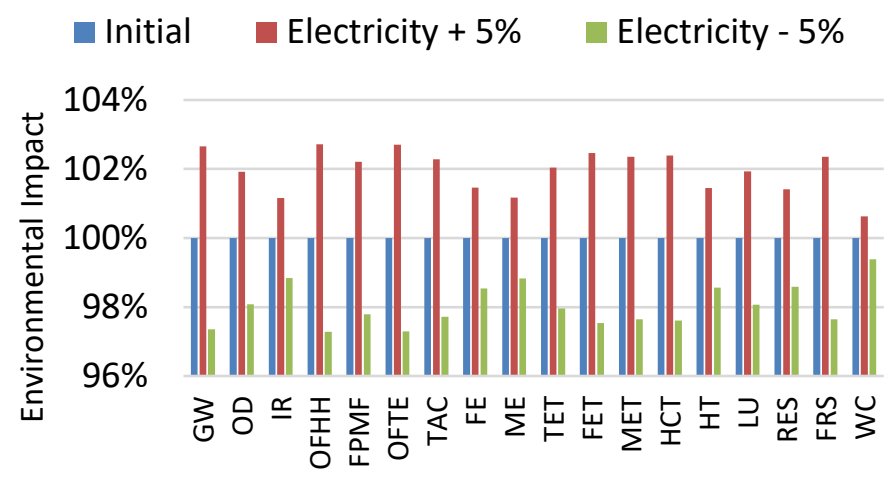

C

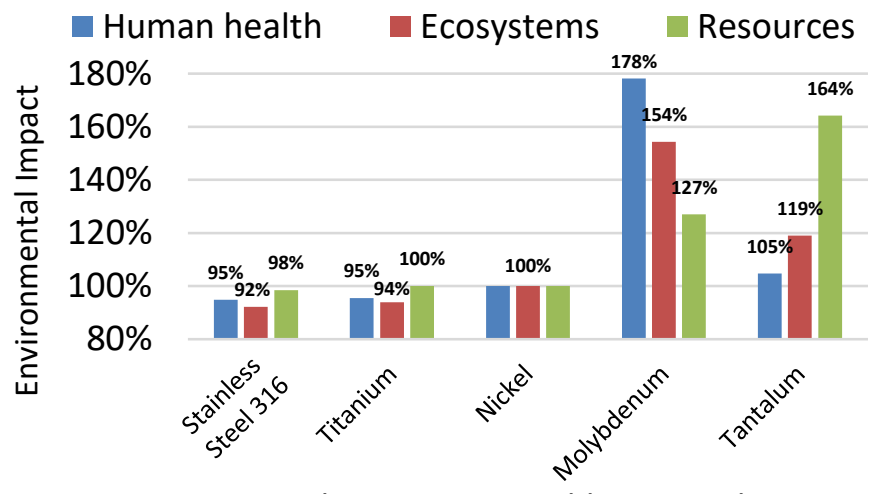

B

- Initial $\quad$ Synthetic Rutile + 5\% $\quad$ Synthetic Rutile - 5\%

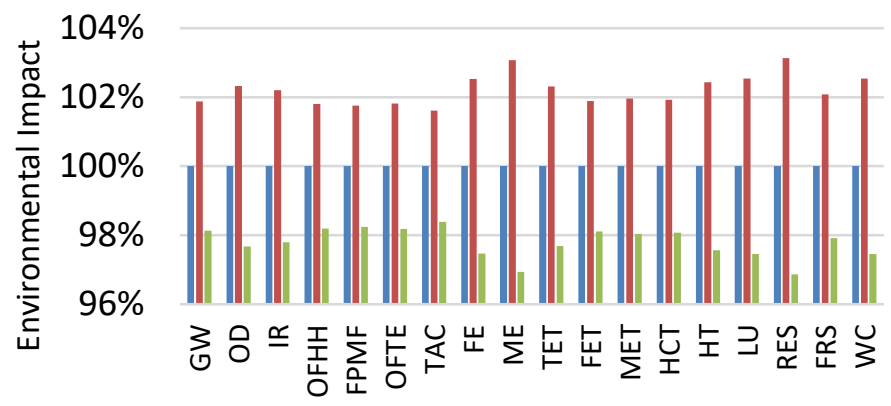

D

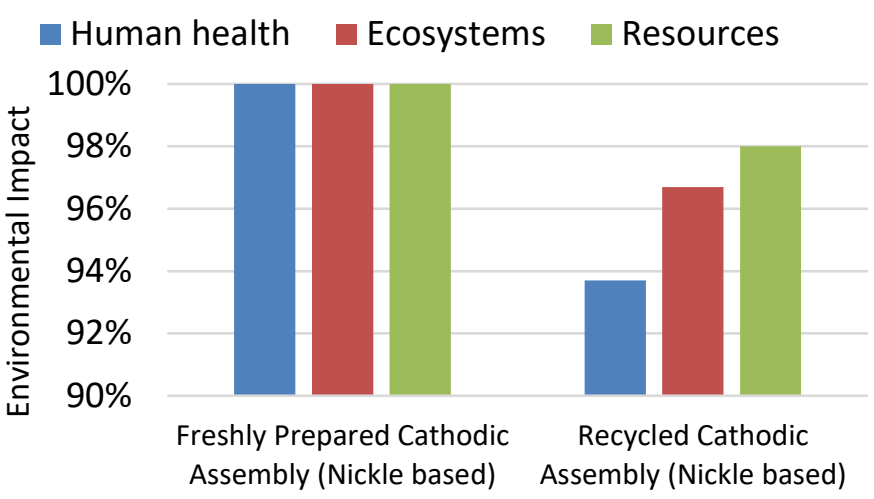

Potential Cathodic Assembly Materials

\section{E}

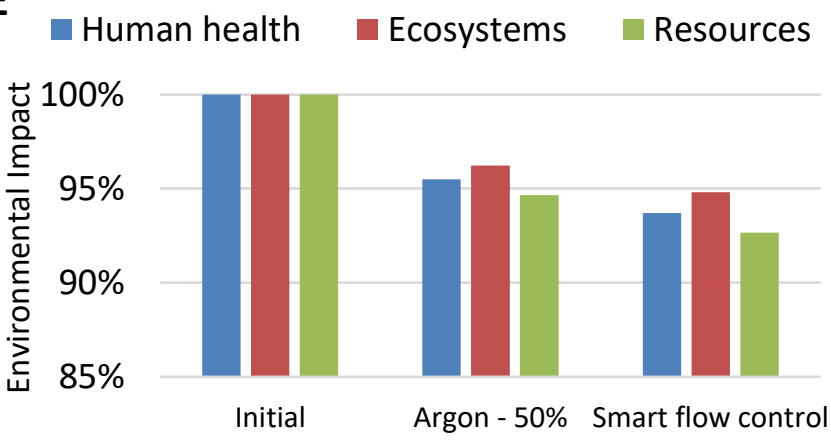

Figure 10: Parametric and Sensitivity Analysis. A - Sensitivity results for electricity change. B - Sensitivity analysis for Synthetic rutile change. C - Relative impact change on the endpoint criteria for the NEM process due to the replaced cathode-wrapping material D - Effect of the implementation of the reusable cathodic assembly. $E$ Relative impact of the improved Argon use scenarios.

the described model was indeed heavily relying on the emissions caused by electricity as the reduction in consumption of $5 \%$ resulted in the reduction across all the categories by $1-3 \%$ (See Figure $10 \mathrm{~A}$ ). Such a response confirms that electricity is a key contributor, however, the reduction of electricity consumption is a complex task, which has been a hot topic among the metallurgical researchers [9].

Following electricity, the sensitivity of the synthetic rutile was conducted showing the similar fluctuation of around $2-3 \%$ for the reduction or increase in the consumption by $5 \%$, demonstrating the stability of the built model. Figure 10 B shows the especially high fluctuation of ME and RES that is closely tied to the mining and purification stages of synthetic rutile production [51]. These factors represent the formation of particulates that affect $M E$ and the increased mineral consumption, which is in a direct connection to RES.

Additionally, the investigation results of the proposed replacement of the current cathodic assembly material, i.e., nickel, are summarised in Figure $\mathbf{1 0}$ C. Tantalum and molybdenum were selected and investigated here as they have been considered to be chemically and thermally stable materials that are suitable for molten salt electrolysis. From Figure $10 \mathrm{C}$ it is clear that the implementation of Stainless Steel 316 as the cathodic assembly material is most beneficial for all 
three of the endpoint criteria, potentially due to the welldeveloped technologies in the steel manufacturing industry. The improvement of such implementation was estimated to be 5, 8 and $2 \%$ for Human health, Ecosystems and Resources respectively, which is only accounted to a total reduction of the environmental impact of the NEM process of about $0.5 \%$. Such a replacement is not yet applicable due to the physical properties of Stainless Steel 316, which is stiffer compared to nickel foam, an important consideration for wrapping synthetic rutile precursors. Nonetheless, the produced evaluation can be used as a guideline when selecting a cathodic material.

The implementation of a recyclable assembly shows the total reduction of 6,3 and $2 \%$ for Human health, Ecosystems and Resources respectively, as seen from Figure $10 \mathrm{D}$. It is important to notice that a proposed assembly is reused and is assumed to not affect the system.

The effect of argon was fully assessed, as seen in Figure $10 \mathrm{E}$, showing that the reduction of the flow of $50 \%$ yields a total improvement of roughly $5 \%$, which is further reduced by $1 \%$ when implementing smart flow control as discussed earlier. This indicates that argon plays a more significant role than the cathodic assembly and is worth investigating into for environmental and financial concerns.

\section{Comparison of the Conventional Kroll-EBM Process and the NEM Process:}

In this study, the proposed NEM Process has been described as an alternative to the Kroll-EBM Process for manufacturing titanium products from synthetic rutile. Figure $\mathbf{1 1}$ shows the relative impacts on the endpoint criteria, showing a $70 \%$ reduction for impacts related to human health and the ecosystem can be achieved by the NEM Process over the KrollEBM Process. Resources are slightly lower, with a $63 \%$ reduction. These differences were expected due to the previous work that compared the Kroll Process and the FFC-Cambridge Process for titanium extraction only, as it was previously reported that the latter was emitting up to $35 \%$ less $\mathrm{CO}_{2}$ [47]. To fully understand the endpoint analysis, the midpoint impact differences of the two manufacturing routes were also compared for the core processes. Figure $\mathbf{1 2}$ represents the life cycle impacts of the two titanium extraction processes that are implemented into the investigated systems.

As seen from Figure 12, five impact categories have been significantly reduced (around $50 \%$ ) by the FFC-Cambridge Process: SOD, IR, FE, ME and FRS. The significant reduction seen for the midpoint categories IR and SOD is primarily due to

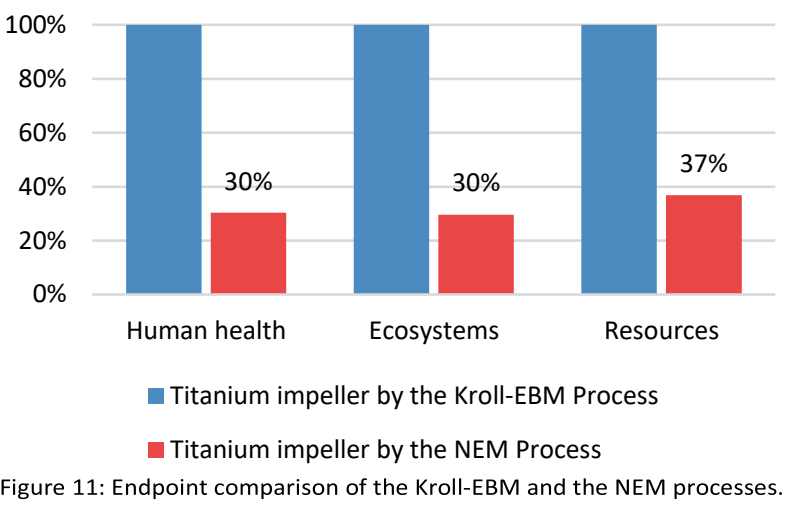

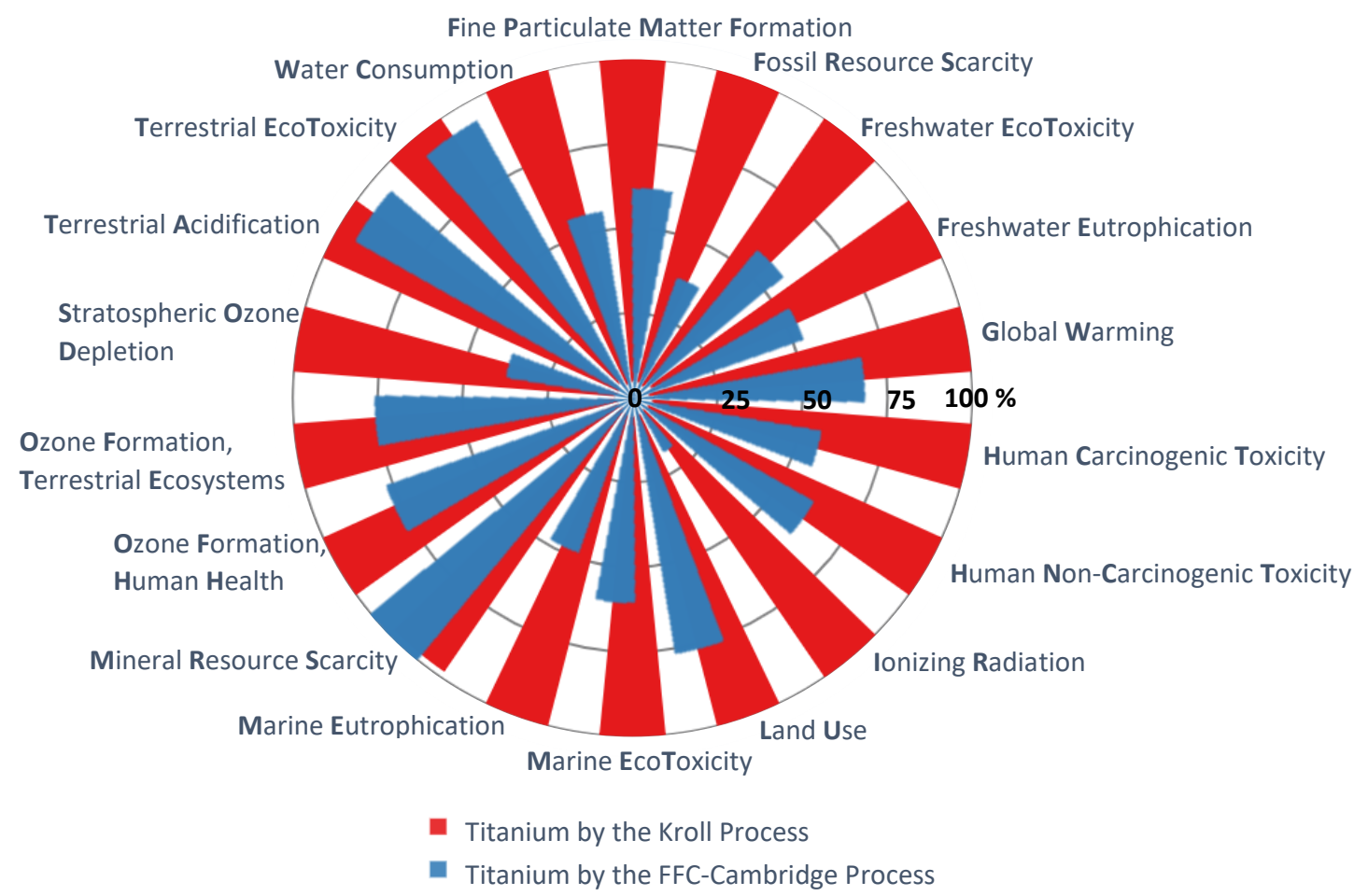

Figure 12: Midpoint comparison for the Kroll and the FFC-Cambridge processes for titanium extraction only. 


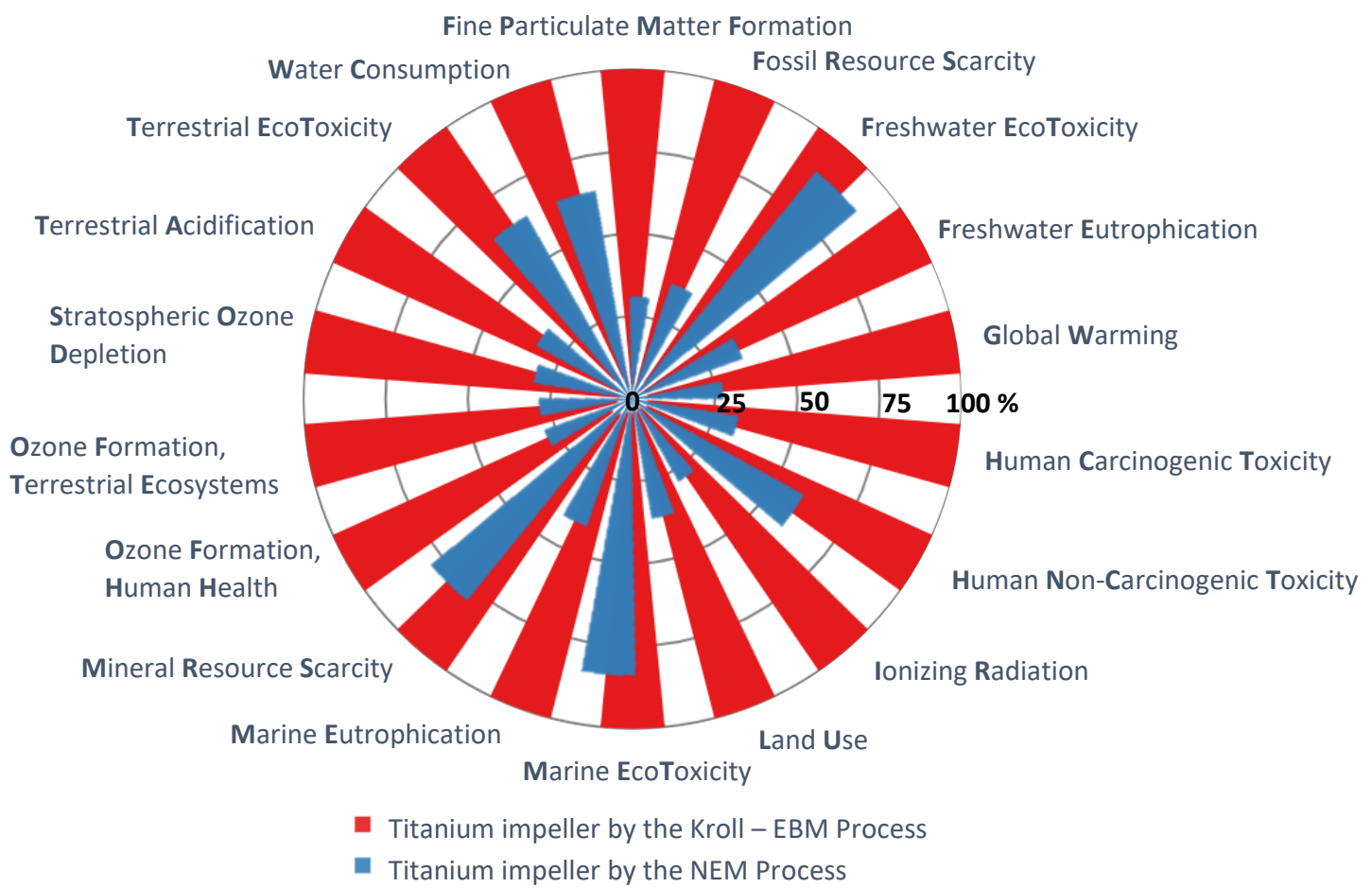

Figure 13: Midpoint comparison of the NEM Process with the EBM route.

chlorine, which is not used in the FFC-Cambridge Process, a substance known to deplete the ozone layer and increase ionizing radiation $[11,68]$. The reduction in the impacts on FE and ME by the FFC-Cambridge Process can be attributed to the elimination of the carbochlorination step, which is necessary for the Kroll Process. The carbochlorination step transforms synthetic rutile into the $\mathrm{TiCl}_{4}$, a main reagent of the Kroll Process. This step also results in the production of $\mathrm{CO}_{2}$ and solid waste that are known to induce excessive growth of plants and algae in both fresh and marine water sources, resulting in depleted oxygen content of the water $[10,69]$. The impact of FRS is associated with the magnesium metal involved in the Kroll Process, which is used for the magnesiothermic reduction of $\mathrm{TiCl}_{4}$. Magnesium production requires enormous amounts of resources due to the current manufacturing technique [70]. Noticeably, the impact of the FFC-Cambridge Process on MRS is about $3 \%$ higher than that of the Kroll Process, this is most likely due to the advanced recycling system of both $\mathrm{Cl}_{2}$ and $\mathrm{Mg}$ used in the Kroll Process and the fact that the FFC-Cambridge Process does not recycle $\mathrm{CaCl}_{2}$. The rest is mostly associated with the different nature of the two processes, one being a metallothermic extraction process (the Kroll Process), and the other one is an electrochemical metallisation process (the FFCCambridge Process) [71].

Midpoint comparison of the two complete routes shows a clear picture of the advantages of the NEM Process (see in Figure 13). The most affected criteria are GW, SOD, IR, OFHH, FPMF, OFTE, TA, FE, ME, HCT, LU and FRS. The main cause, in this case, is the dramatic reduction in the electricity consumption on the DIW stage when compared to that consumed by the EBM (11.39 $\mathrm{kWh} / 1$ titanium impeller - EBM; $0.29 \mathrm{kWh} / 1$ titanium impeller -
DIW). Additionally, SOD, IR, FE, ME and FRS are reduced during the final stage of the process with the implementation of the FFC-Cambridge Process, as discussed for Figure 12. Overall, there is a consistent trend of reducing environmental impacts by applying the NEM Process.

\section{Legislations}

Following the example of the laws enforced by the EPA on the territory of the US and the legislation adopted by the EU regarding the emissions, it was important to look at the parameters indicated in those entities. In the US, the EPA has allocated high importance to pollutants such as $\mathrm{NO}_{\mathrm{x}}, \mathrm{SO}_{2}$ and PM2.5 in both the Clean Air Act and Air Enforcement statement [72]. This is comparable with the EU list that also contains $\mathrm{CO}_{2}-$ a commonly considered indicator for greenhouse effects and consequent environmental degradation [73]. Therefore, Table 4 summarises the main contributors towards the emission of those pollutants. Following the data, the dramatic reduction of the emissions of the above-stated pollutants means that, upon the implementation of the NEM Process, established thresholds for any pollutant can be reduced twofold with no effect on the production volumes. Therefore, the proposed method has a huge potential to replace the established conventional route in case of further restrictions within the future law enforcing acts. 
Table 4: Legislation cantered emissions.

\begin{tabular}{|c|c|c|c|c|}
\hline & Unit & $\begin{array}{c}\text { Kroll- } \\
\text { EBM } \\
\text { route }\end{array}$ & $\begin{array}{c}\text { The } \\
\text { NEM } \\
\text { Proces } \\
\mathrm{s}\end{array}$ & $\begin{array}{c}\text { Percentag } \\
\text { reduction }\end{array}$ \\
\hline $\begin{array}{c}\text { Global } \\
\text { warming }\end{array}$ & $\mathrm{kg} \mathrm{CO}_{2}$ eq & 244.21 & 63.75 & $74 \%$ \\
\hline $\begin{array}{c}\text { Terrestrial } \\
\text { acidification }\end{array}$ & $\mathrm{kg} \mathrm{SO}_{2}$ eq & 0.94 & 0.29 & $69 \%$ \\
\hline $\begin{array}{c}\text { Fine } \\
\text { particulate } \\
\text { matter } \\
\text { formation }\end{array}$ & $\mathrm{kg} \mathrm{PM2.5} \mathrm{eq}$ & 0.41 & 0.12 & $71 \%$ \\
\hline $\begin{array}{c}\text { Ozone } \\
\text { formation }\end{array}$ & $\mathrm{kg} \mathrm{NO}_{\mathrm{x}}$ eq & 1.09 & 0.28 & $74 \%$ \\
\hline
\end{tabular}

\section{Conclusion}

This study has compared the Near-net-shape Electrochemical Metallisation (NEM) Process with the conventionally utilised Kroll Process for titanium extraction and the Electron Beam Melting (EBM) for titanium fabrication (i.e., the Kroll-EBM Process). According to the Life Cycle Analysis (LCA), when using the Kroll-EBM Process as the benchmark, the reduction of the impact for the ecosystem and human health achieved by the NEM Process was established to be $70 \%$. In addition, it was pointed out that using the same starting point of synthetic rutile the NEM Process takes three days to complete, while the KrollEBM Process takes roughly two weeks. Furthermore, the results from this comparative impact assessment clearly demonstrated that the NEM Process can significantly improve the sustainability of titanium fabrication by about $67 \%$ when using the Kroll-EBM Process as the benchmark.

The contribution analysis indicated potential improvements that can be done to further reduce the observed environmental impacts of the NEM Process. Significant improvements could be achieved from the optimisation of the FFC Metallisation stage, where the use of nickel and the amount of spent argon contribute to a relatively high impact. It was proposed that the use of nickel foam could be mitigated by replacing it with stainless steel or titanium. Furthermore, utilisation of the reusable nickel foam-based cathode assembly was shown to have the highest reduction in environmental impacts, measuring up to $10 \%$. Argon use was observed to impact 5 of the 18 categories, which is possible to be reduced by $5 \%$ by implementing a better reactor design or utilising a smart flow control. Due to the simplistic nature of the DIW method, there is not much space for further optimising the current shaping process involved in the NEM Process.

Overall, for the first time, this work demonstrates a quantitative assessment on the environmental impact from one of the evolving titanium fabrication processes, i.e., the NEM Process and compares it with the conventionally used Kroll-EBM Process. This could exert a far-reaching impact for the cleaner metallurgy and manufacturing techniques, considering that progressively more countries and regions have proposed and implemented new environmental policies like emission trading scheme for energy-intensive sectors.

\section{Conflict of interest}

There are no conflicts of interest to declare.

\section{Acknowledgement}

This work is supported by Natural Science Foundation of China (51804172), and Ningbo Science and Technology Innovation 2025 Key Project (2018B10029)

\section{References.}

1 Ryan G, Pandit A, Apatsidis DP. Fabrication methods of porous metals for use in orthopaedic applications. Biomaterials. 2006;27(13):2651-70.

2 Grimm MJ. SELECTION OF MATERIALS FOR BIOMEDICAL APPLICATIONS. In: Kutz $M$, editor. Handbook of Materials Selection. New York: John Wiley \& Sons 2002.

3 Group TI. Titanium for Architectural Applications. 2006.

4 Group TI. Titanium for Aerospace Alloys \& Applications. 2002.

5 Group TI. Titanium for Automotive Applications. 2006.

6 Gorynin IV. Titanium alloys for marine application. Materials Science and Engineering A. 1999;263(2):112-6.

7 Schutz RW, Watkins HB. Recent developments in titanium alloy application in the energy industry. Materials Science and Engineering A. 1998;243(1-2):305-15.

8 Donachie MJ. Titanium: a technical guide: ASM International; 2000.

9 Hu D, Dolganov A, Ma M, Bhattacharya B, Bishop MT, Chen GZ. Development of the Fray-Farthing-Chen Cambridge Process: Towards the Sustainable Production of Titanium and Its Alloys. JOM. 2018;70(2):129-37.

10 Gao F, Nie Z, Yang D, Sun B, Liu Y, Gong X, et al. Environmental impacts analysis of titanium sponge production using Kroll process in China. Journal of Cleaner Production. 2018;174:771-9.

11 Kroll W, editor The Production of Ductile Titanium. Transactions of the Electrochemical Society; 1940 October 3rd; Ottawa, Canada.

12 EHK Technologies. Summary of Emerging Titanium Cost Reduction Technologies. 2004.

13 Zhang $Y$, Fang ZZ, Sun $P$, Zhang $T$, Xia $Y$, Zhou $C$, et al. Thermodynamic destabilization of Ti-O solid solution by $\mathrm{H} 2$ and deoxygenation of $\mathrm{Ti}$ using $\mathrm{Mg}$. Journal of the American Chemical Society. 2016;138(22):6916-9.

14 Pal UB, Woolley DE, Kenney GB. Emerging SOM technology for the green synthesis of metals from oxides. JOM. 2001;53(10):32-5.

15 Ono K, Suzuki RO. A New Concept for Producing Ti Sponge: Calciothermic Reduction. JOM. 2002;54(2):59 - 61.

16 Wu C, Tan M, Ye G, Fray DJ, Jin X. High-Efficiency Preparation of Titanium through Electrolysis of Carbo-Sulfurized Titanium Dioxide. ACS Sustainable Chemistry \& Engineering. 2019;7(9):8340-6.

17 Chen GZ, Fray DJ, Farthing TW. Direct electrochemical reduction of titanium dioxide to titanium in molten calcium chloride. Nature. 2000;407(6802):361-4.

18 Maha Vishnu DS, Sanil N, Shakila L, Sudha R, Mohandas KS, Nagarajan K. Electrochemical reduction of $\mathrm{TiO} 2$ powders in molten calcium chloride. Electrochimica Acta. 2015;159:12430 . 
19 Hu D, Xiao W, Chen G. Near-Net-Shape Production of Hollow Titanium Alloy Components via Electrochemical Reduction of Metal Oxide Precursors in Molten Salts. Metallurgical and Materials Transactions B. 2013;44(2):272-82.

20 Peng J, Jiang K, Xiao W, Wang D, Jin X, Chen GZ. Electrochemical Conversion of Oxide Precursors to Consolidated $\mathrm{Zr}$ and $\mathrm{Zr}-2.5 \mathrm{Nb}$ Tubes. Chemistry of Materials. 2008;20(23):7274-80.

21 Le VT, Paris H. A life cycle assessment-based approach for evaluating the influence of total build height and batch size on the environmental performance of electron beam melting. The International Journal of Advanced Manufacturing Technology. 2018;98(1):275-88.

22 Darsin M, Basuki HA. Development Machining of Titanium Alloys: A Review. Applied Mechanics and Materials. 2014;493:492-500.

23 Pramanik A. Problems and solutions in machining of titanium alloys. The International Journal of Advanced Manufacturing Technology. 2014;70(5):919-28.

24 Machado AR, Wallbank J. Machining of Titanium and its Alloys $-a$ Review. Proceedings of the Institution of Mechanical Engineers, Part B: Journal of Engineering Manufacture. 1990;204(1):53-60.

25 Erhard B, Christoph L, Frank P. Mechanical Properties of Additive Manufactured Ti-6Al-4V Using Wire and Powder Based Processes. IOP Conference Series: Materials Science and Engineering. 2011;26(1):012004.

26 Dehghan-Manshadi A, Bermingham MJ, Dargusch MS, StJohn $\mathrm{DH}$, Qian M. Metal injection moulding of titanium and titanium alloys: Challenges and recent development. Powder Technology. 2017;319:289-301.

27 Kobryn PA, Semiatin SL. The laser additive manufacture of $\mathrm{Ti}-$ 6Al-4V. JOM. 2001;53(9):40-2

28 Murr LE, Quinones SA, Gaytan SM, Lopez MI, Rodela A, Martinez EY, et al. Microstructure and mechanical behavior of Ti-6Al-4V produced by rapid-layer manufacturing, for biomedical applications. Journal of the Mechanical Behavior of Biomedical Materials. 2009;2(1):20-32.

$29 \mathrm{Ma}$ Q. COLD COMPACTION AND SINTERING OF TITANIUM AND ITS ALLOYS FOR NEAR-NET-SHAPE OR PREFORM FABRICATION. International Journal of Powder Metallurgy. 2010;46(5):29-44

30 Baufeld B, Biest OVd, Gault R. Additive manufacturing of Ti$6 \mathrm{Al}-4 \mathrm{~V}$ components by shaped metal deposition Microstructure and mechanical properties. Materials \& Design. 2010;31, Supplement 1(0):S106-S11.

31 Kottman M, Zhang S, McGuffin-Cawley J, Denney P, Narayanan BK. Laser Hot Wire Process: A Novel Process for Near-Net Shape Fabrication for High-Throughput Applications. JOM. 2015;67(3):622-8.

32 Weston NS, Jackson M. FAST-forge - A new cost-effective hybrid processing route for consolidating titanium powder into near net shape forged components. Journal of Materials Processing Technology. 2017;243:335-46.

33 Herzog D, Seyda V, Wycisk E, Emmelmann C. Additive manufacturing of metals. Acta Materialia. 2016;117:371-92.

34 Nandwana P, Kirka MM, Paquit VC, Yoder S, Dehoff RR. Correlations Between Powder Feedstock Quality, In Situ Porosity Detection, and Fatigue Behavior of Ti-6Al-4V Fabricated by Powder Bed Electron Beam Melting: A Step Towards Qualification. JOM. 2018;70(9):1686-91.

$35 \mathrm{Moll} \mathrm{JH}$. Utilization of gas-atomized titanium and titaniumaluminide powder. JOM. 2000;52(5):32-4.

36 Smagorinski M, Tsantrizos G. Proceedings of the 2002 World Congress on Powder Metallurgy \& Particulate Materials. 1989.

37 Guo KK, Liu CS, Dong HH, Chen SY. Effect of Extension Length of Catheter on Properties of TC4 Powder Prepared by
Electrode Induction Melting Gas Atomization. Dongbei Daxue Xuebao/Journal of Northeastern University. 2018;39(6):797802.

38 Chen G, Zhao SY, Tan P, Wang J, Xiang CS, Tang HP. A comparative study of Ti-6Al-4V powders for additive manufacturing by gas atomization, plasma rotating electrode process and plasma atomization. Powder Technology. 2018;333:38-46.

39 McCracken CG, Motchenbacher C, Barbis DP. REVIEW OF TITANIUM-POWDER-PRODUCTION METHODS. International Journal of Powder Metallurgy. 2010;46(5):19-26.

40 Sun P, Fang ZZ, Zhang Y, Xia Y. Review of the Methods for Production of Spherical $\mathrm{Ti}$ and $\mathrm{Ti}$ Alloy Powder. JOM. 2017;69(10):1853-60.

41 Sun J, Peng Z, Zhou W, Fuh JYH, Hong GS, Chiu A. A Review on 3D Printing for Customized Food Fabrication. Procedia Manufacturing. 2015;1:308-19.

42 Peng E, Zhang D, Ding J. Ceramic Robocasting: Recent Achievements, Potential, and Future Developments. Advanced Materials. 2018;30(47):1802404.

43 Oosthuizen SJ. In search of low cost titanium: the Fray Farthing Chen (FFC) Cambridge process. J S Afr I Min Metall. 2011;111(3):199-202.

44 Jotzo F, Karplus V, Grubb M, Löschel A, Neuhoff K, Wu L, et al. China's emissions trading takes steps towards big ambitions. Nature Climate Change. 2018;8(4):265-7.

45 Bakhtiari S. Coming Out Clean: Australian Carbon Pricing and Clean Technology Adoption. Ecological Economics. 2018;154:238-46.

46 Murray B, Rivers N. British Columbia's revenue-neutral carbon tax: A review of the latest "grand experiment" in environmental policy. 2015;86:674-83.

47 Norgate TE, Jahanshahi S, Rankin WJ. Assessing the environmental impact of metal production processes. Journal of Cleaner Production. 2007;15(8):838-48.

48 Institution TBS. Environmental management - Life cycle assessment - Principles and framework. 2006

49 Institution TBS. Environmental management - Life cycle assessment - Requirements and guidelines. 2018.

50 Zhang K, Mei J, Wain N, Wu X. Effect of Hot-Isostatic-Pressing Parameters on the Microstructure and Properties of Powder Ti-6Al-4V Hot-Isostatically-Pressed Samples. Metallurgical and Materials Transactions A. 2010;41(4):1033-45.

51 Zhang W, Zhu Z, Cheng CY. A literature review of titanium metallurgical processes. Hydrometallurgy. 2011;108(34):177-88

52 Mellor I, Grainger L, Rao K, Deane J, Conti M, Doughty G, et al. Titanium powder production via the Metalysis process. Elsevier; 2015. p. 51-67.

53 Sure J, Vishnu DSM, Schwandt C. Direct electrochemical synthesis of high-entropy alloys from metal oxides. Applied Materials Today. 2017;9:111-21.

54 Ma M, Wang D, Wang W, Hu X, Jin X, Chen GZ. Extraction of titanium from different titania precursors by the FFC Cambridge process. Journal of Alloys and Compounds. 2006;420(1-2):37-45.

55 Serres N, Tidu D, Sankare S, Hlawka F. Environmental comparison of MESO-CLAD ${ }^{\circledR}$ process and conventional machining implementing life cycle assessment. Journal of Cleaner Production. 2011;19(9):1117-24.

56 Baumers M, Tuck C, Hague R, Ashcroft I, Wildman R. A COMPARATIVE STUDY OF METALLIC ADDITIVE MANUFACTURING POWER CONSUMPTION. SOLID FREEFORM FABRICATION PROCEEDINGS. 2010:278-88.

57 Murr LE, Gaytan SM, Ceylan A, Martinez E, Martinez JL, Hernandez $\mathrm{DH}$, et al. Characterization of titanium aluminide alloy components fabricated by additive manufacturing using electron beam melting. Acta Materialia. 2010;58(5):1887-94. 
58 Ecoinvent. Ecoinvent database. Ecoinvent. 2018(3.0).

59 Le VT, Paris H, Mandil G. Environmental impact assessment of an innovative strategy based on an additive and subtractive manufacturing combination. Journal of Cleaner Production. 2017;164:508-23.

60 PRÉ. SimaPro. PRÉ CONSULTANTS BV. 2018(8.5.2.0)

61 Goedkoop M, Heijungs R, Huijbregts M, Schryver AD, Struijs J, Zelm Rv. ReCiPe 2008 Report I: Characterisation. 1st ed. The Netherlands: National Institute for Public Health and the Environment. Ministry of Health, Welfare and Sport.; 2013.

62 Middlemas S, Fang ZZ, Fan P. Life cycle assessment comparison of emerging and traditional Titanium dioxide manufacturing processes. Journal of Cleaner Production. 2015;89:137-47.

63 Weir G, Muneer T. Energy and environmental impact analysis of double-glazed windows. Energy Conversion and Management. 1998;39(3):243-56.

64 Bernstein JT. CRYOGENIC ARGON PRODUCTION. Modern Air Separation Plant Technology Conference. 1999.

65 Schmidt T, Buchert M, Schebek L. Investigation of the primary production routes of nickel and cobalt products used for $\mathrm{Li}$ ion batteries. Resources, Conservation and Recycling. 2016;112:107-22.

66 Leyssens L, Vinck B, Van Der Straeten C, Wuyts F, Maes L. Cobalt toxicity in humans $-A$ review of the potential sources and systemic health effects. Toxicology. 2017;387:43-56.

67 EPA. CompTox Chemicals Dashboard. 2018;2018(12.20).

68 Steinbrecht W, Hegglin MI, Harris N, Weber M. Is global ozone recovering? Comptes Rendus Geoscience. 2018;350(7):368 75.

69 Henriksson PJG, Rico A, Zhang W, Ahmad-Al-Nahid S, Newton $\mathrm{R}$, Phan LT, et al. Comparison of Asian Aquaculture Products by Use of Statistically Supported Life Cycle Assessment. Environmental Science \& Technology. 2015;49(24):14176-83.

70 Gao F, Nie Z-R, Wang Z-H, Gong X-Z, Zuo T-Y. Assessing environmental impact of magnesium production using Pidgeon process in China. Transactions of Nonferrous Metals Society of China. 2008;18(3):749-54.

71 Fray DJ. New Methods for the Production of Titanium. International Materials Reviews. 2008;53(6):317.

72 EPA. the Clean Air Act. United States. 1970;42 U.S.C. §7401 et seq.

73 European Parliament. Directive 2010/75/EU of the European Parliament and of the Council of 24 November 2010 on industrial emissions (integrated pollution prevention and control). THE EUROPEAN PARLIAMENT AND THE COUNCIL OF THE EUROPEAN UNION. 2010: Chapter 15 Volume 015 P. 159 $-261$. 